\title{
Storm Tracks and Climate Change
}

\author{
Lennart Bengtsson and Kevin I. Hodges \\ Environmental System Science Centre, University of Reading, Reading, United Kingdom \\ ERICH ROECKNER \\ Max Planck Institute for Meteorology, Hamburg, Germany
}

(Manuscript received 25 April 2005, in final form 11 September 2005)

\begin{abstract}
Extratropical and tropical transient storm tracks are investigated from the perspective of feature tracking in the ECHAM5 coupled climate model for the current and a future climate scenario. The atmosphere-only part of the model, forced by observed boundary conditions, produces results that agree well with analyses from the 40-yr ECMWF Re-Analysis (ERA-40), including the distribution of storms as a function of maximum intensity. This provides the authors with confidence in the use of the model for the climate change experiments. The statistical distribution of storm intensities is virtually preserved under climate change using the Intergovernmental Panel on Climate Change (IPCC) Special Report on Emissions Scenarios (SRES) A1B scenario until the end of this century. There are no indications in this study of more intense storms in the future climate, either in the Tropics or extratropics, but rather a minor reduction in the number of weaker storms. However, significant changes occur on a regional basis in the location and intensity of storm tracks. There is a clear poleward shift in the Southern Hemisphere with consequences of reduced precipitation for several areas, including southern Australia. Changes in the Northern Hemisphere are less distinct, but there are also indications of a poleward shift, a weakening of the Mediterranean storm track, and a strengthening of the storm track north of the British Isles. The tropical storm tracks undergo considerable changes including a weakening in the Atlantic sector and a strengthening and equatorward shift in the eastern Pacific. It is suggested that some of the changes, in particular the tropical ones, are due to an SST warming maximum in the eastern Pacific. The shift in the extratropical storm tracks is shown to be associated with changes in the zonal SST gradient in particular for the Southern Hemisphere.
\end{abstract}

\section{Introduction}

The mobile extratropical cyclones play a dominant role in the climate at middle and high latitudes: first, by having a primary role in determining the local weather and its typical variation and thereby exercising a strong influence on precipitation, cloudiness, and radiation and their variation in time and space; second, by having an important role in the general circulation of the atmosphere via their strong influence on the vertical and horizontal exchange of heat, water vapor, and momentum; and third, by interacting with the large-scale atmospheric centers of action such as blocking and other

Corresponding author address: Kevin I. Hodges, Environmental System Science Centre, University of Reading, Harry Pitt Building, 3 Earley Gate, Whiteknights, Reading RG6 6AL, United Kingdom.

E-mail: kih@mail.nerc-essc.ac.uk semistationary patterns that may dominate the regional weather on the time scales of weeks (Lau 1988; Ting and Held 1990). Any systematic change in the intensity, frequency, or position of the storm tracks will consequently have a far-reaching influence on the local climate.

The climate of Europe, for example, is strongly dominated by the mobile cyclones. It was noted in earlier studies (van Loon and Rogers 1978, and references therein) that the Atlantic cyclones often moved in preferred tracks, either in a northeasterly direction over the Norwegian Sea bringing heavy precipitation to northwestern Europe and generally mild weather for most areas, or on a more southerly track with high precipitation in southern Europe and at least during the winter period bringing cold weather to northern Europe. These fluctuations in the storm tracks are related to variations in the large-scale atmospheric circulation, such as the North Atlantic Oscillation (NAO; Rogers 
1997; Hurrell et al. 2003) or Arctic Oscillation (AO; Thompson and Wallace 1998). However, whether the variations in the NAO are a cause of the variations in the storm track or a consequence thereof is an open question. Other influences on the storm tracks, particularly in the Western Hemisphere, are related to the El Niño-Southern Oscillation (ENSO; Zhang et al. 1997).

In the Tropics a large part of the tropical belt is dominated by traveling easterly waves. During the warm season the easterly waves sometimes develop into tropical storms and hurricanes (Thorncroft and Hodges 2001). Both empirical studies (Gray 1979) and modeling studies (Bengtsson et al. 1995) suggest that sea surface temperatures higher than around $26^{\circ} \mathrm{C}$ are necessary conditions, although by no means sufficient, for the development of hurricanes. Atmospheric conditions are equally important including low vertical wind shear and sufficiently high relative humidity through the troposphere.

Numerical simulations with general circulation models at sufficient resolution have demonstrated considerable skill in reproducing extratropical storm tracks (Bengtsson 1991) as well as moderate skill in simulating tropical storms (Camargo and Sobel 2004). This includes skill in modeling the response to ENSO (Shukla et al. 2000). The intense core of the tropical storms is mostly underestimated mainly because of insufficient horizontal resolution (Bengtsson et al. 1997), but the tracks as well as the number of tropical storms are generally well described by the more advanced (in terms of resolution and physical parameterizations) general circulation models (Bengtsson et al. 1995; Sugi et al. 2002).

In this paper two key scientific objectives are addressed: first, to explore how an advanced general circulation model is capable of simulating the observed storm tracks. This is done by comparing the simulated storm tracks of the European Centre/Hamburg Model Version 5 (ECHAM5; Roeckner et al. 2003) in an Atmospheric Model Intercomparison Project 2 (AMIP2) study over a 20-yr period (E. Roeckner et al. 2005, unpublished manuscript) with the analyses of storm tracks in the 40-yr European Centre for MediumRange Weather Forecasts (ECMWF) Re-Analysis (ERA-40; Uppala et al. 2005). The AMIP study consists of three realizations starting from slightly different initial states. The second objective is to investigate how the storm tracks may change in a future climate. For this the data from a recent series of climate change experiments with the coupled climate model of the Max Planck Institute for Meteorology (Jungclaus et al. 2006) are used.

The scenario used for the climate change experiments is based upon the Special Report on Emission
Scenarios (SRES; Nakicenovic et al. 2000). The scenario used is A1B and two 30-yr periods are compared-1961-90, representing the present climate, and 2071-2100, representing a future climate at a time when carbon dioxide concentration has virtually doubled. For the period prior to the year 2000 observed greenhouse gases and aerosols were used for the forcing. Data are available for a small ensemble of three for each period making it possible to roughly identify the spread between the members as compared to the overall difference between the two periods. Using this data a systematic evaluation of transient storm tracks has been conducted for climate change. The statistical distribution of transient eddies with respect to their intensity has been investigated as well as geographical changes in the storm tracks. Possible causes for the changes identified will also be discussed.

The approach used in this investigation is to identify each individual storm in a Lagrangian framework and to follow each storm from its cyclogenesis to its cyclolysis. In the extratropics several similar studies have been performed previously for climate change scenarios and for particular models. For example, Carnell et al. (1996; $\left.2.5^{\circ} \times 3.75^{\circ}, \mathrm{L} 11\right)$, Schubert et al. (1998; T42L19), Sinclair and Watterson (1999; R21L9), Leckebusch and Ulbrich $\left(2004 ; 2.5^{\circ} \times 3.75^{\circ}, \mathrm{L} 19\right)$, and Geng and Sugi (2003; T106L21), who give a good summary of previous work in this area. These studies have all used this approach applied to the mean sea level pressure (MSLP) field either as the raw field or by deriving the geostrophic vorticity from it. The data used in most of these studies have been derived from relatively low resolution integrations of the respective GCMs as indicated by the information (atmosphere only) following the references above. Geng and Sugi (2003) are an exception in using higher-resolution data. There have also been several studies where extratropical cyclones are identified but not tracked (Lambert 1995; Zhang and Wang 1997; Fyfe 2003) predominately using MSLP. This range of studies has presented a mixed picture as to the changes in extratropical cyclones with climate change. Some models predict a reduction in the number of cyclones but with an increase in the number of more intense cyclones; some indicate a poleward shift in the storm tracks whilst other studies suggested no significant change in the cyclone characteristics. The reduction in the number of cyclones can be understood in terms of a reduction in the baroclinicity associated with a reduction in the pole-to-equator temperature gradient (some models show a reduction at low levels compensated by an increase at upper levels) whilst the increase in the intensity may be the result of increased latent heat release (diabatic heating) associated with 
the increase of water vapor in the atmosphere in a warmer climate. The sea surface temperature (SST) gradients (Inatsu and Hoskins 2004; Inatsu et al. 2002) have also been shown to play a role in the position and activity of the storm tracks. Tropical convection can also have an impact on the upper-tropospheric storm tracks through the generation of Rossby waves (Inatsu and Hoskins 2004). Changes in any of these processes may have an impact on cyclones in the future, and the fact that these are competing processes may explain the wide range of results produced by different models that handle the delicate balance between these processes differently.

The increase in the intensity of the more intense cyclones may also be related to the field used, in particular MSLP, and may actually reflect changes in the largescale background pressure field, so that identification of cyclones in the raw MSLP (as pressure minima) may be reflecting these changes rather than actual changes in the storm intensities. This is likely to be less prevalent in methods that use the Laplacian of MSLP to identify the cyclones or that use a completely different field that is less influenced by the large-scale background, such as relative vorticity. This aspect is also addressed in this study (see discussion).

In terms of tropical activity most previous climate change studies have focused on tropical cyclones (Knutson and Tuleya 2004; McDonald et al. 2005, and other references therein) rather than the whole range of synoptic-scale activity, that is, tropical easterly waves. Previous climate change studies have indicated a mixed picture, as with the extratropical cyclones, with some studies indicating a reduction in number though intensification of tropical cyclones, although this appears to depend on the ocean basin (McDonald et al. 2005).

In this study both extratropical and tropical activity is explored using the Lagrangian approach applied to data from a more recent model, integrated at a higher resolution than typically used in the past. It is believed that this will lead to a deeper insight into the behavior of transient waves both in the tropical and the extratropical circulation and will more accurately determine how present climate models are capable of simulating the number of storms, their generation, their intensity and geographical distribution, and the way they may change in the future.

The paper continues in section 2 with a description of the model and the climate change experiments; in section 3 the analysis methodology is described; and in section 4 the results for the AMIP2 study are compared with those from atmospheric reanalyses from ERA-40 (Uppala et al. 2005). In section 5 the differences be- tween the period 1961-90 and the period 2071-2100 are compared. In section 6 the results are discussed, including comments and consequences for regional climate change.

\section{Model description and experiments}

\section{a. The coupled model}

The coupled model consists of new versions for both the atmosphere and the ocean components. In the atmosphere model (Roeckner et al. 2003) vorticity, divergence, temperature, and the logarithm of surface pressure are represented by a truncated series of spherical harmonics with triangular truncation 63 (T63), whereas the advection of water vapor, cloud liquid water, and cloud ice is treated by a flux-form semi-Lagrangian scheme. A hybrid sigma/pressure system is used in the vertical direction (31 layers with the top model level at $10 \mathrm{hPa}$ ). The model uses state-of-the-art parameterizations for shortwave and longwave radiation, stratiform clouds, cumulus convection, boundary layer and land surface processes, and gravity wave drag.

The Max Planck Institute Ocean Model (MPI-OM; Marsland et al. 2003) employs the primitive equations for a hydrostatic Boussinesq fluid with a free surface. The vertical discretization is on $40 z$ levels, and the bottom topography is resolved by means of partial grid cells. The ocean has a nominal resolution of $1.5^{\circ}$ and the poles of the curvilinear grid are shifted to land areas over Greenland and Antarctica. The parameterization of physical processes include along-isopycnal diffusion, horizontal tracer mixing by advection with unresolved eddies, vertical eddy mixing, near-surface wind stirring, convective overturning, and slope convection. Concentration and thickness of sea ice are calculated by means of a dynamic and thermodynamic sea ice model.

In the coupled model (Jungclaus et al. 2006), the ocean passes to the atmosphere the SST, sea ice concentration, sea ice thickness, snow depth on ice, and the ocean surface velocities. The atmosphere runs with these boundary values for one coupling time step (one day) and accumulates the forcing fluxes. These fluxes are then transferred to the ocean. In addition to wind stress, the heat and freshwater fluxes are passed to the ocean for the calculation of the turbulent wind mixing. All fluxes are calculated separately for ice-covered and open water partitions of the grid cells. River runoff and glacier calving are treated interactively in the atmosphere model and the respective freshwater fluxes are passed to the ocean together with the atmospheric precipitation minus evaporation field. A special feature of the coupled model is that the surface wind stress over the ocean is calculated relative to the ocean current. 
This considerably reduces the cold bias in the equatorial Pacific. The model does not employ flux adjustments.

\section{b. The AMIP2 experiment}

In addition to the coupled model runs, three AMIPstyle simulations were performed for the time period 1979-99, using the atmospheric component of the coupled model without any changes except for the specification of greenhouse gas concentrations, solar constant, and SSTs according to the AMIP2 protocol (WGNE 1996). In addition to the resolution of T63 used in the integrations, limited higher-resolution integrations at T106 and T159 have also been explored.

\section{c. The climate change experiments}

The coupled model was run at preindustrial atmospheric concentrations of carbon dioxide $\left(\mathrm{CO}_{2}\right)$, methane $\left(\mathrm{CH}_{4}\right)$, and nitrous oxide $\left(\mathrm{N}_{2} \mathrm{O}\right)$ for about $500 \mathrm{yr}$. During this time no notable climate drift could be identified in the atmosphere and in the upper part of the ocean. For example, the linear trend in annual global mean surface air temperature was negligibly small $\left(0.026 \mathrm{~K} \mathrm{century}^{-1}\right)$.

The so-called twentieth-century runs for the time period 1860-2000 were initialized at three different states, in both the atmosphere and the ocean, of the preindustrial control run. Well-mixed greenhouse gases $\left(\mathrm{CO}_{2}\right.$, $\mathrm{CH}_{4}, \mathrm{~N}_{2} \mathrm{O}, \mathrm{F} 11^{*}$, and $\mathrm{F} 12$ ) were prescribed as annual global means according to observations (fit to ice core data and direct observations), where F11* also includes the effect of the minor halocarbons. Monthly data of stratospheric and tropospheric ozone concentrations were prescribed as two-dimensional (latitude; height) distributions. The spatiotemporal distribution of sulphate aerosols was prescribed using the respective data from an offline simulation (Pham et al. 2005). Both the direct and first indirect (cloud albedo) effect of sulfate was included. No natural forcing was applied in the twentieth-century runs. The three realizations of the twentieth century were extended into the twenty-first century (2001-2100) according to Intergovernmental Panel on Climate Change (IPCC) SRES scenario A1B. There are therefore three realizations for the twentiethcentury and twenty-first-century climates. In this study we use the $30-\mathrm{yr}$ periods (for each ensemble member) of 1961-90 and 2071-2100, hereafter referred to as $20 \mathrm{C}$ and $21 \mathrm{C}$, respectively.

\section{Data and analysis methodology}

The means by which the various simulations, AMIP, 20C, 21C, and the ERA-40 reanalysis are diagnosed follows closely the analysis of Hoskins and Hodges (2002, 2005) for the extratropical storm tracks and Thorncroft and Hodges (2001) for the tropical easterly waves and tropical cyclones. This entails the identification and tracking of weather systems in data available at 6-hourly time steps and the derivation of statistics for their distribution and mean attributes. This is done using the objective tracking system of Hodges (1995, 1996, 1999). For the extratropics the MSLP or the geostrophic vorticity (computed from the MSLP; Sinclair and Watterson 1999) fields are often used for these types of studies, but here we use the relative vorticity field at $850 \mathrm{hPa}$. This is considered a better field to use for identifying lower-tropospheric cyclones as it does not depend on extrapolation to any large extent, it is less influenced by the large-scale background, and it focuses on the small-scale end of the synoptic range. This field is also used for the tropical analysis. However, the relative vorticity field at moderate to high resolution can be a very noisy field to use for tracking studies. Hence, the analysis of extratropical and tropical cyclones is performed at a spectral resolution of T42 on a Gaussian grid for all datasets. This allows the same spatial synoptic scales to be identified for each dataset. As in Hoskins and Hodges $(2002,2005)$ for the extratropical analysis a background field is also removed before performing the identification and tracking, by setting the coefficients in the spherical harmonic expansion of the field at each time step to zero for total wavenumbers $\mathrm{n} \leq 5$. This is not strictly necessary for vorticity but does help in the identification for some other fields such as MSLP and is used here for consistency. The positive and negative anomalies are both tracked separately, allowing both cyclones and anticyclones to be identified depending on the field used.

The tracking analysis is of general applicability and is not limited to the $850-\mathrm{hPa}$ relative vorticity; a wide range of fields have been explored and some of these additional fields will also be discussed in this paper where suitable. Prior to computing the statistics the track ensembles are filtered to retain only those systems that last at least 2 days ( 8 time steps) and travel further than $1000 \mathrm{~km}$. This allows us to focus on the mobile systems, which have the greatest impact on the climate. The spatial statistics are derived from the track ensembles using spherical kernel methods (Hodges 1996), which compute the statistics directly on the sphere making the statistics independent of projection biases. The tracking and statistics are computed for seasonal periods in the extratropics of DecemberFebruary (DJF), March-May (MAM), June-August (JJA), and September-November (SON) and in the Northern Hemisphere (NH) Tropics for the period 
May-October (MJJASO). In addition composite statistics are also computed for ENSO using the monthly Niño-3 $\left(5^{\circ} \mathrm{N}-5^{\circ} \mathrm{S}, 150^{\circ}-90^{\circ} \mathrm{W}\right) \mathrm{SST}$ index to provide additional weights to the statistical estimation for the positive and negative phases (see the appendix).

To provide some indication of the significance for difference maps of the spatial statistics, $p$ values (the probability that a more extreme value is possible) are also computed using a permutation Monte Carlo approach (sampling without replacement). The sampling distribution is assumed to be asymmetric and both tails are considered (asymmetric, two-tail test). This can be computationally intensive, so the sample size is limited to 2000 , but has the benefit that it is nonparametric and makes no assumptions about the data. By sampling on the whole tracks we also take into account the correlation of the data within the tracks though not any correlation between tracks. This approach also has the benefit that the $p$ values can be determined for a whole suite of statistics without having to resort to different tests for different statistics (further details will appear in a future publication). However, the $p$ value estimates should only be considered as indicative at the moment because of uncertainty in how the sampling should be best performed. The $p$ values are plotted for values below $5 \%$.

\section{Storm tracks in the present climate}

In this section the storm tracks derived from the ERA-40 reanalyses (Uppala et al. 2005) for the period 1979-2003 are contrasted with those obtained from the three-ensemble AMIP integrations of ECHAM5 (Roeckner et al. 2004) available for the period 1979-99 to explore and validate the model response to the prescribed boundary forcing. As an example of what the storm tracks look like using the 850 -hPa relative vorticity, Fig. 1 shows the storm tracks for the 2002/03 NH DJF winter as calculated from ERA-40.

\section{a. Northern Hemisphere extratropics}

Figures 2a,c show the NH 850-hPa relative vorticity $\left(\xi_{850}\right)$, extratropical storm track spatial statistics based on ERA-40 for the boreal winter (DJF), including the track density and mean intensity (Fig. 2a) and the cyclogenesis (Fig. 2c). The cyclogenesis statistic shows that generation of vortices occurs throughout the storm track regions but is more pronounced in well-restricted areas, suggesting orographic forcing and local ocean heat fluxes as the main causes. Two key areas of cyclogenesis can be found on the eastern side of the Rocky Mountains, one over New Mexico and Colorado and another one on the eastern side of the Canadian Rockies. These areas are significantly stronger than the genesis region on the east coast of the United States. Another region of pronounced cyclogenesis can be found over the western Mediterranean Sea. Over Asia two major cyclogenesis regions stand out, one on the eastern slopes of Tibet and another east of Japan, again stressing the importance of orographic forcing and areas of strong sensible and latent heat fluxes from the ocean. Figure $2 \mathrm{c}$ agrees with the previous study of Hoskins and Hodges (2002) based on 15-yr ECMWF Re-Analysis (ERA-15) data and broadly agrees with synoptically produced maps of cyclogenesis (Petterssen 1956).

The storm tracks (Fig. 2a) emanating from their genesis regions extend generally several thousands of kilometers downstream. In some areas, such as over the eastern North Atlantic, there are indications that the storms are reactivated. The largest mean intensity is found over the northwestern Pacific and in the Atlantic Ocean south of Greenland, suggesting an important contribution of the transient eddies to the mean field of large-scale vorticity associated with surface low pressure centers in the northern Pacific (Aleutian low) and in the northern Atlantic (Icelandic low).

Finally, the cyclolysis (not shown) occurs throughout the storm track regions as well as in relatively confined regions such as the Gulf of Alaska and Vancouver region, northeastern Canada, eastern Mediterranean, and central Russia. These results all accord with the previous study of Hoskins and Hodges (2002).

Figures $2 b$,d show results for the AMIP simulation by the ECHAM5 model, averaged over the three realizations, and covering broadly the same period as the chosen ERA-40 analyses. The areas of cyclogenesis are rather similar to that of ERA-40 but with some differences. Some genesis regions are more intense in the simulation such as the maximum around the Caspian Sea and over southern China, others are more pronounced in ERA-40 such as the center east of Japan and in the lee of the Rockies. This may point to some model deficiencies such as too little ice cover in the Caspian Sea, the representation of orographic processes (resolution dependence) or to the inability to respond to the sharp SST gradients such as east of Japan. Some differences may also be due to deficiencies in the data assimilation to properly handle the assimilation of weak vorticity centers. The distribution of storms and their mean intensities (Fig. 2b) shows a remarkably good correspondence with ERA-40 for the Atlantic, Pacific, Mediterranean, and Siberian storm tracks, although as with the genesis regions there are 


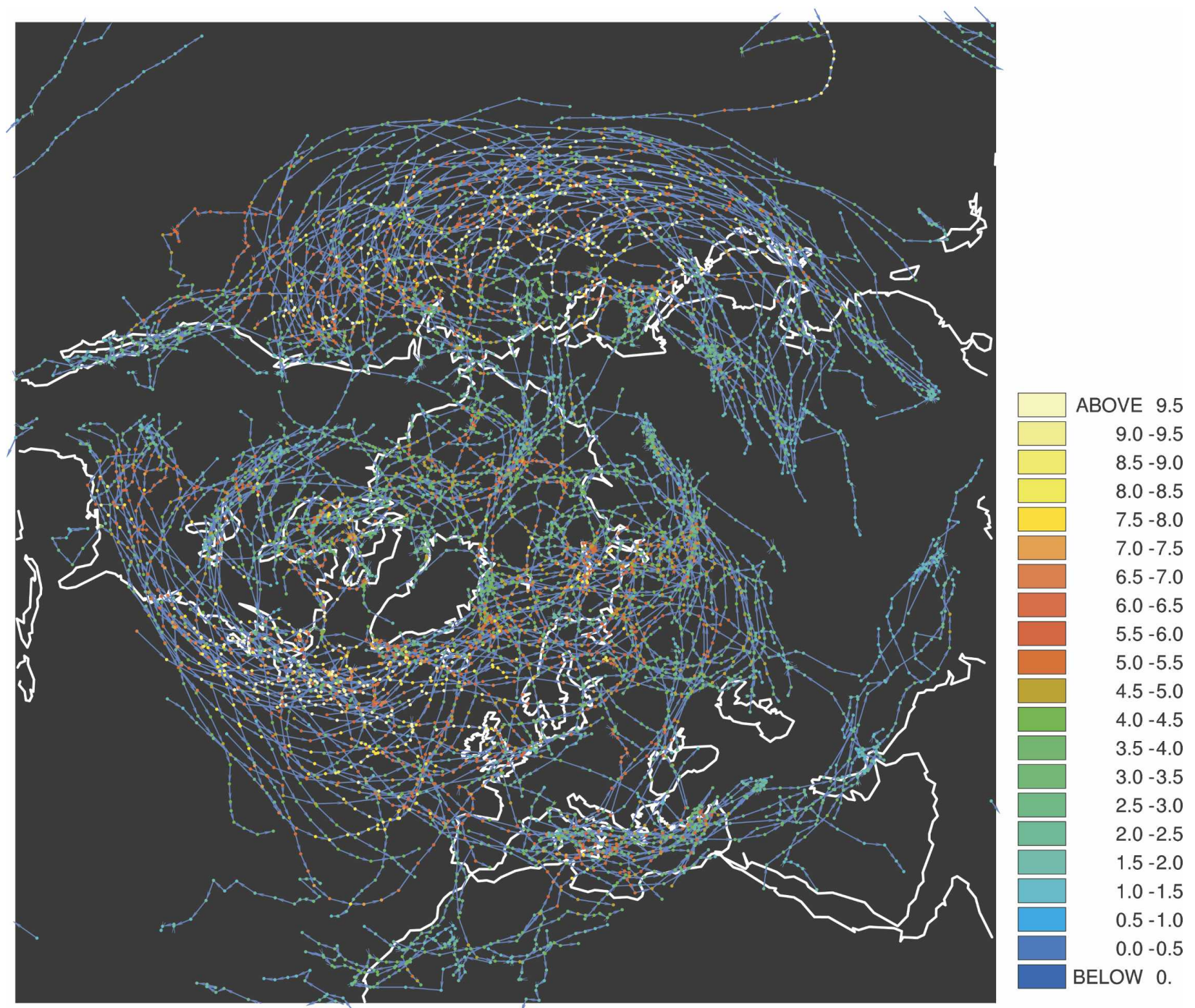

FIG. 1. Example of extratropical cyclone tracks for the DJF winter of 2002/03 from ERA-40 based on the relative vorticity at $850 \mathrm{hPa}$. Only systems that last longer than 2 days and travel farther than $1000 \mathrm{~km}$ are included. Tracks are the blue lines and the colored dots indicate the intensity at each 6-hourly time step along the track in units of $10^{-5} \mathrm{~s}^{-1}$.

some systematic differences. These include the Pacific track density and mean intensity, which appear slightly weaker than in ERA-40, whilst the mean intensities in the Atlantic also appear weaker and the track density a little broader (and perhaps more zonal through Great Britain). This good agreement between ERA-40 and ECHAM5 provides us with confidence that the ECHAM5 model can produce a good representation of extratropical storms.

In Fig. 3 the number of individual storms per month and for each season, respectively, are displayed as a function of their maximum intensity obtained over the lifetime of the storm. The agreement between the AMIP, ECHAM5 integration, and ERA-40 is very good. The number of weaker systems $\left(<7 \times 10^{-5} \mathrm{~s}^{-1}\right)$ is slightly larger in the model run for all three members, but the number of more intense systems and their distribution is practically identical for ERA-40 and the three AMIP integrations for each season. The cause of the larger number of weaker vortices in the model run is not very clear, but it could mean that the ERA-40 system may underestimate such weaker storms as a result of observational and/or assimilation deficiencies. Alternatively, the model may amplify weaker systems too much. However, the overall impression is that the performance of the model compares very well with the reanalysis of ERA-40. Larger differences may become more obvious in these distributions for smaller regions 

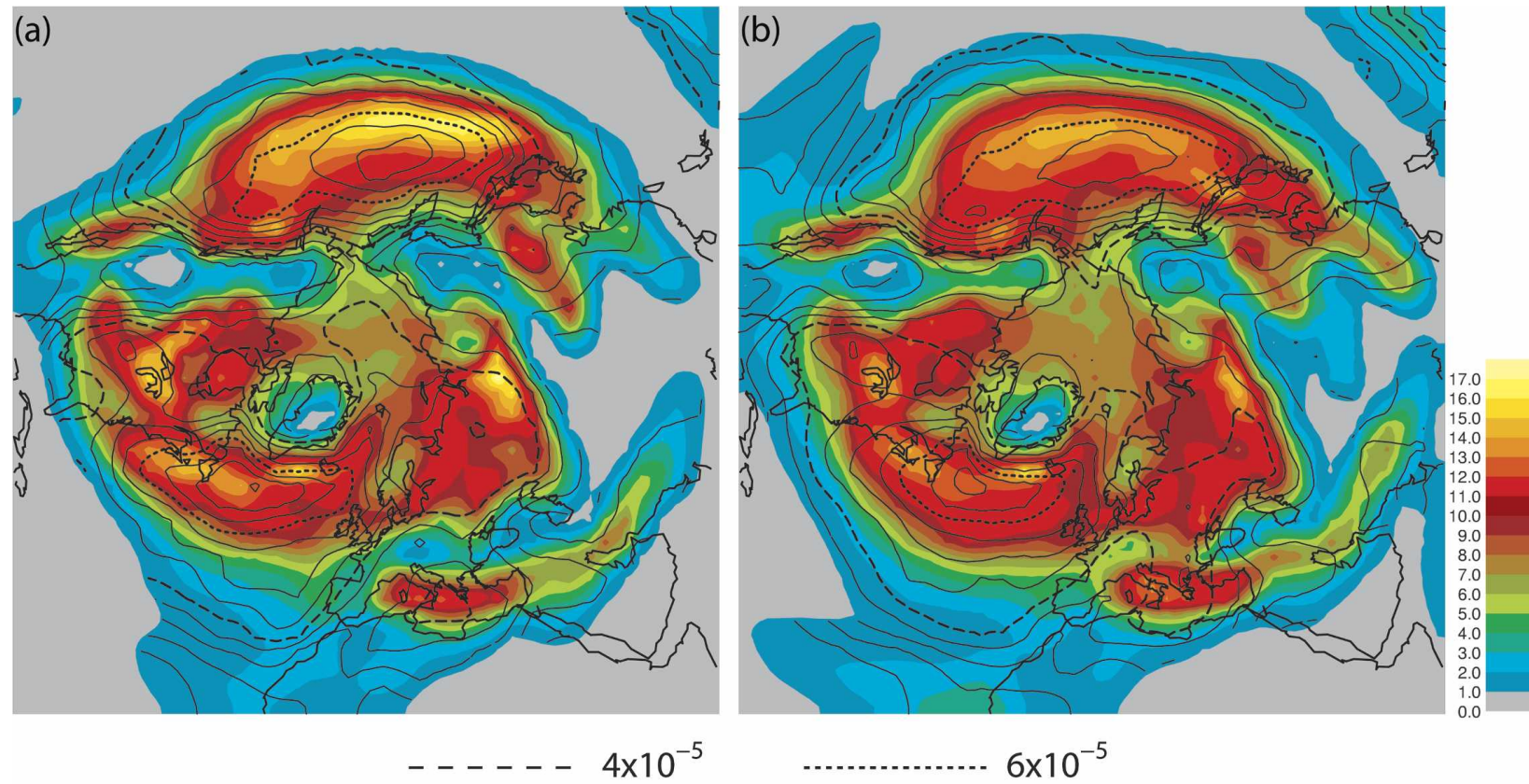

\section{$6 \times 10^{-5}$}
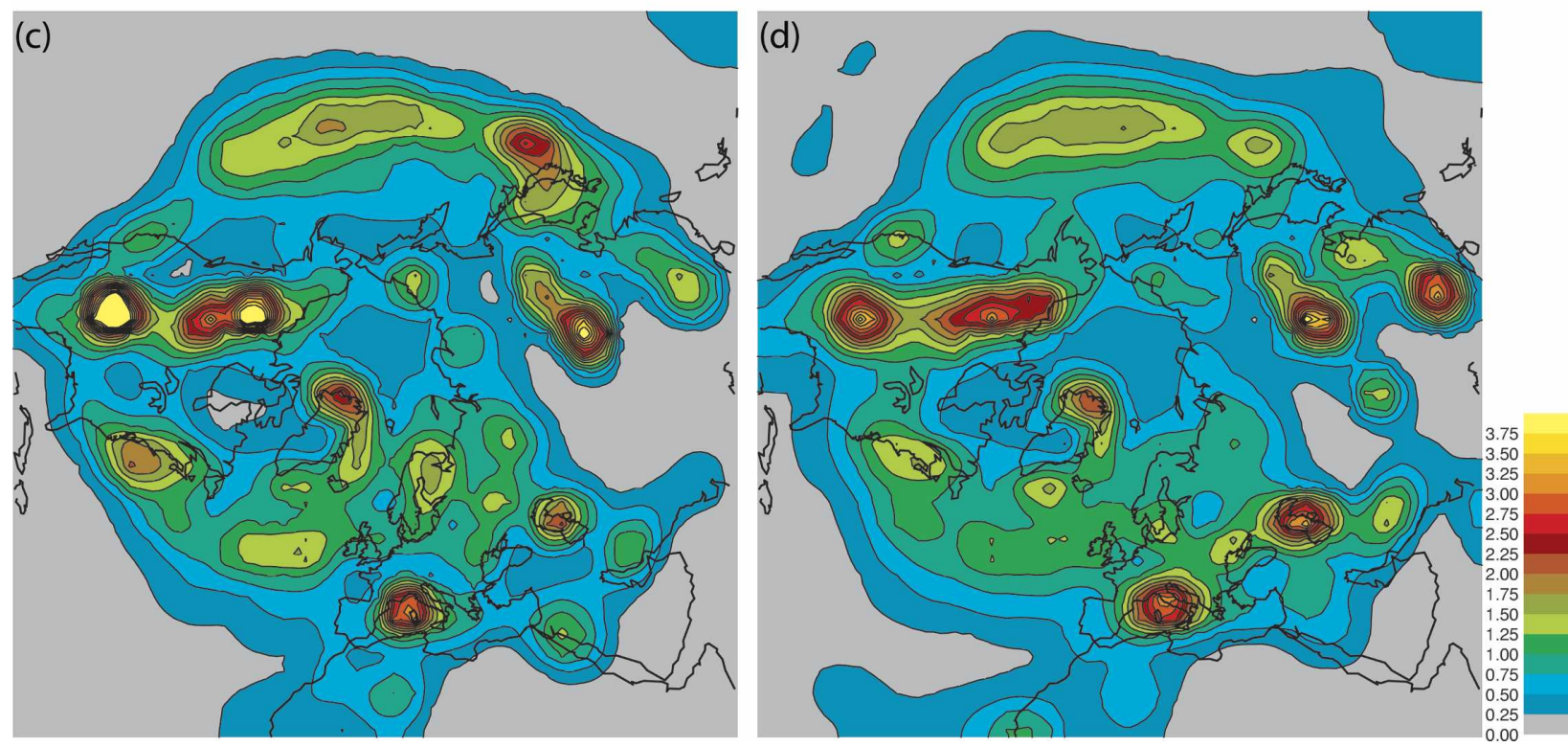

FIG. 2. NH DJF $\xi_{850}$ cyclonic storm track statistics for ERA-40 (1979-2002) and ECHAM5 (AMIP, averaged over three realizations): (a) ERA-40 track density (color) and mean intensity (line), (b) ECHAM5 track density (color) and mean intensity (line), (c) ERA-40 cyclogenesis density, and (d) ECHAM5 cyclogenesis density. Densities are number density per unit area per month where the unit area is equivalent to a $5^{\circ}$ spherical cap $\left(\sim 10^{6} \mathrm{~km}^{2}\right)$ and mean intensities are in units of $10^{-5} \mathrm{~s}^{-1}$. Dashed lines indicate specific mean intensities.

than the whole hemisphere used here, reflecting the differences discussed above.

\section{b. Southern Hemisphere extratropics}

Figure 4 shows the storm track statistics for the Southern Hemisphere (SH) winter (JJA). For ERA-40 the generation of cyclones (Fig. 4c) occurs throughout the storm track regions but with preferred regions occurring to the east of the southern Andes. The area of cyclogenesis is extended both northward and southward along the same longitude with the southern area extending to the northern part of the Antarctic Peninsula. These areas of cyclogenesis are more confined in the $\mathrm{SH}$ summer and more extended in the other sea- 


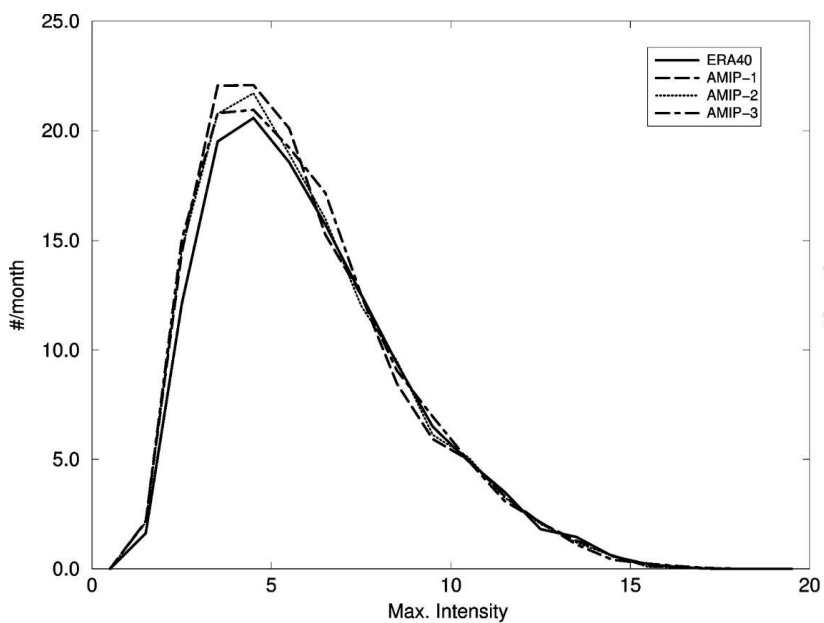

(a)

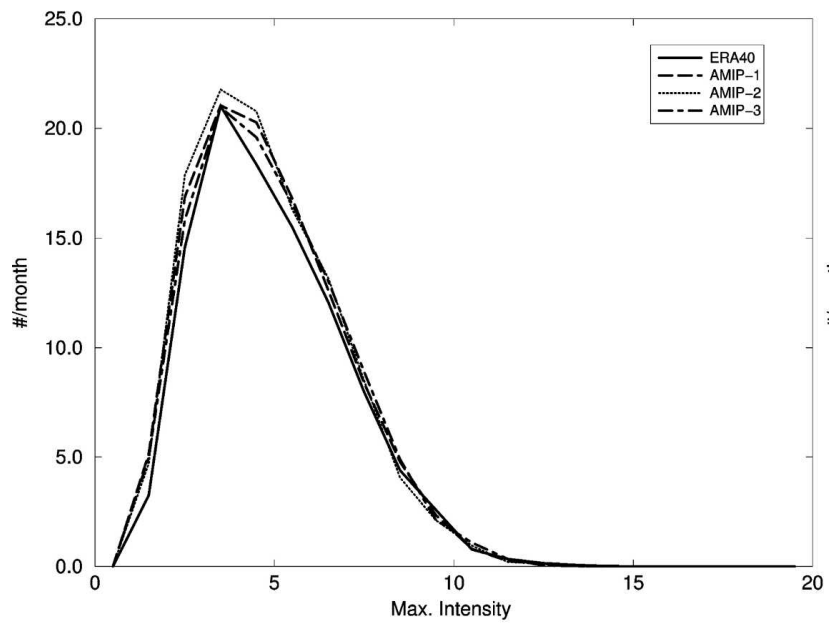

(c)

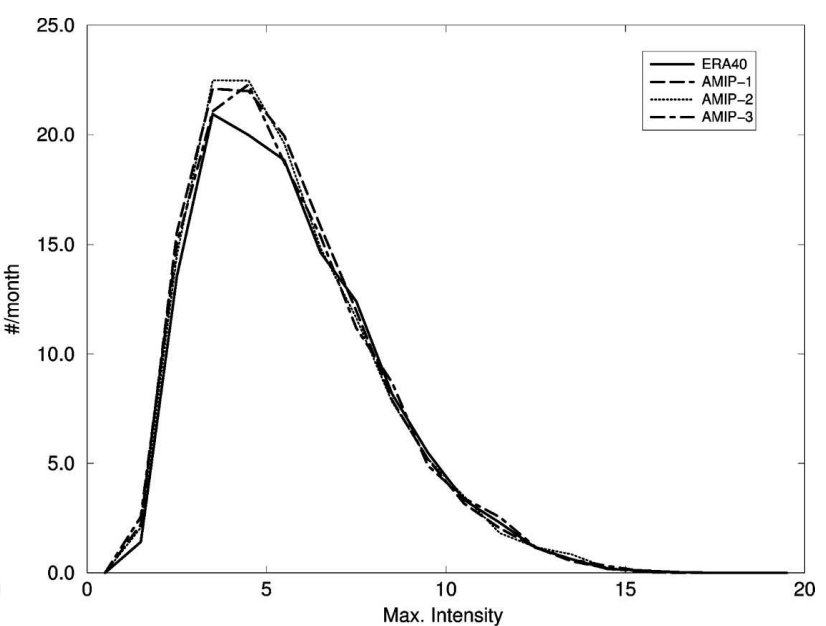

(b)

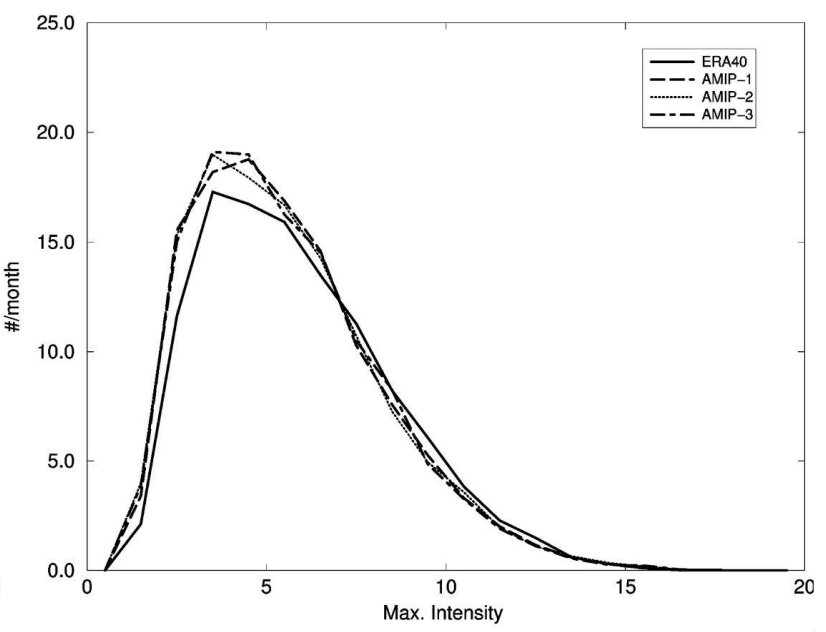

(d)

FIG. 3. Distributions of the number of $\xi_{850}$ cyclonic storms per month vs their maximum intensity for ERA-40 and the three ensemble members of the AMIP ECHAM5 integrations for the NH, for each season, poleward of $30^{\circ} \mathrm{N}$ : (a) DJF, (b) MAM, (c) JJA, and (d) SON. Intensity is in units of $10^{-5} \mathrm{~s}^{-1}$; bin width is $1 \times 10^{-5} \mathrm{~s}^{-1}$.

sons. These regions of cyclogenesis accord well with those in the study of Hoskins and Hodges (2005) using the whole ERA-40 dataset. They highlight that the Patagonia genesis maximum is on the downslope side of where the deep Pacific storm track meets the upslope side of the Andes and cyclolysis occurs (not shown), whilst the more equatorward genesis maximum is more likely associated with the shallow but strong systems on the subtropical jet that cross the Andes here. Another marked center of cyclogenesis is on the Antarctic coast south of Tasmania; this has been associated with the secondary development or reinvigoration associated with storms spiraling in from higher latitudes where they get an influx of cold air from the continent. These then propagate along the Antarctic coast to the Penin- sula. For most of the year the storm tracks in the SH are close to zonal with a maximum intensity around $50^{\circ} \mathrm{S}$. However in JJA (Fig. 4a) the storm tracks are at their most asymmetric and found in two bands between Australia and South America, which spiral in toward Antarctica. A distinct minimum is found around the southern tip of New Zealand, an area where blocking highs are relatively common during the $\mathrm{SH}$ winter (Wiedenmann et al. 2002). The largest storm intensity occurs for all seasons in the Atlantic and Indian Ocean sectors. The general picture is one of genesis at midlatitudes with storms spiraling toward Antarctica and cyclolysis around the Antarctic coast (not shown). Inatsu and Hoskins (2004) have highlighted the importance of both the distribution of orography and the asymmetry 


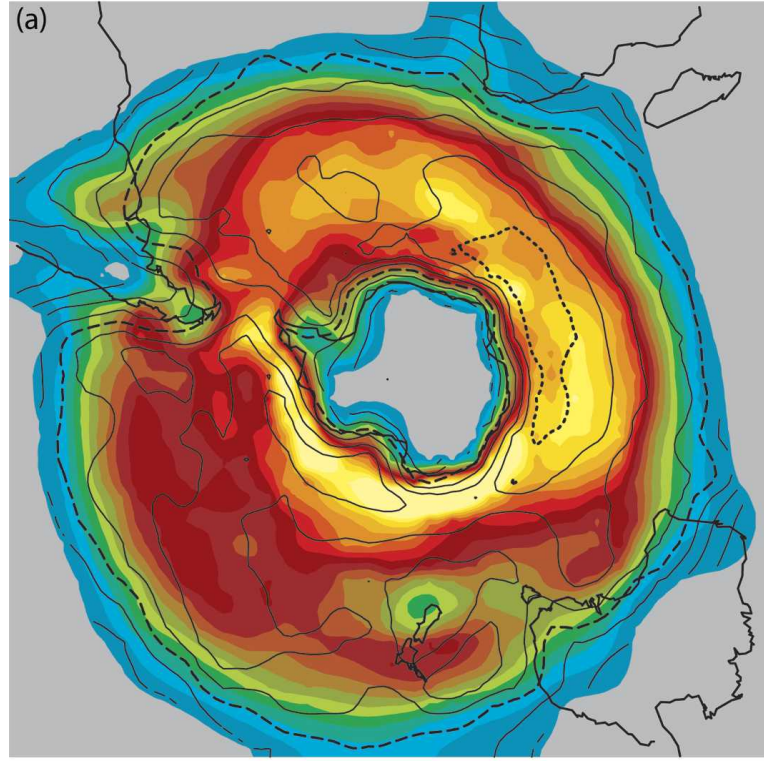

$$
\text { - - - - } 4 \times 10^{-5}
$$

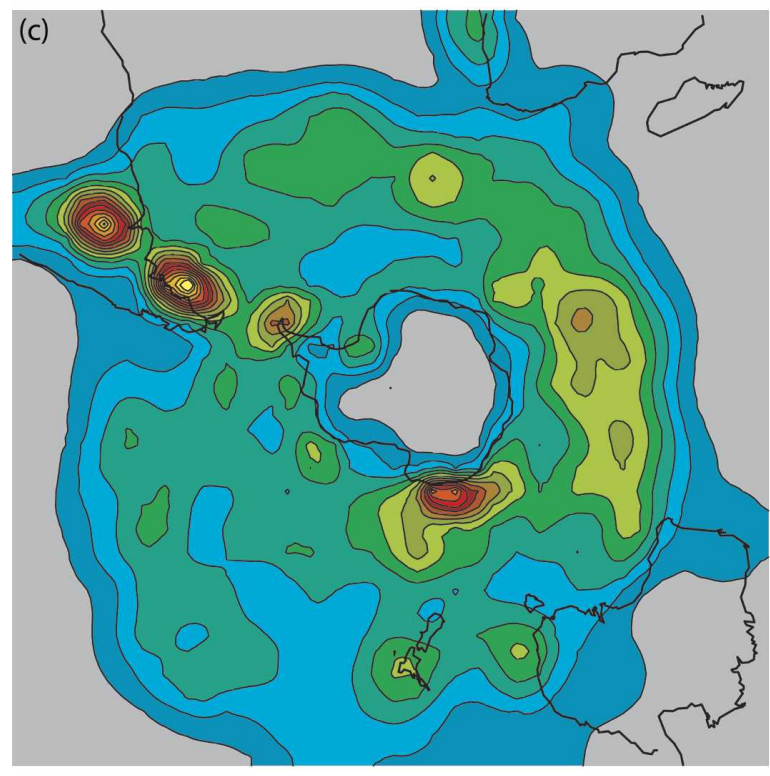

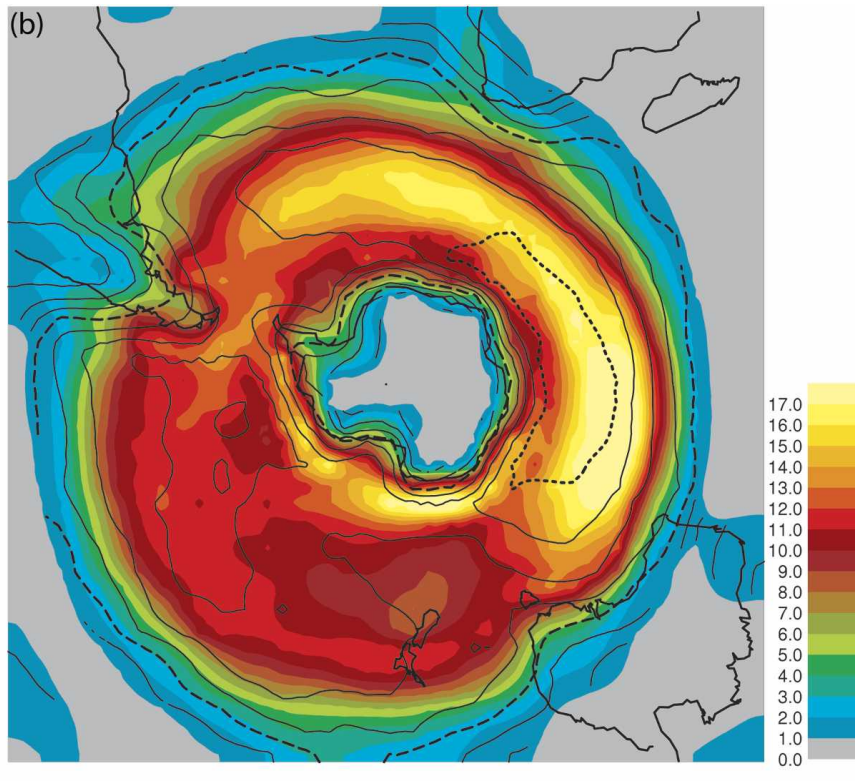

$6 \times 10^{-5}$

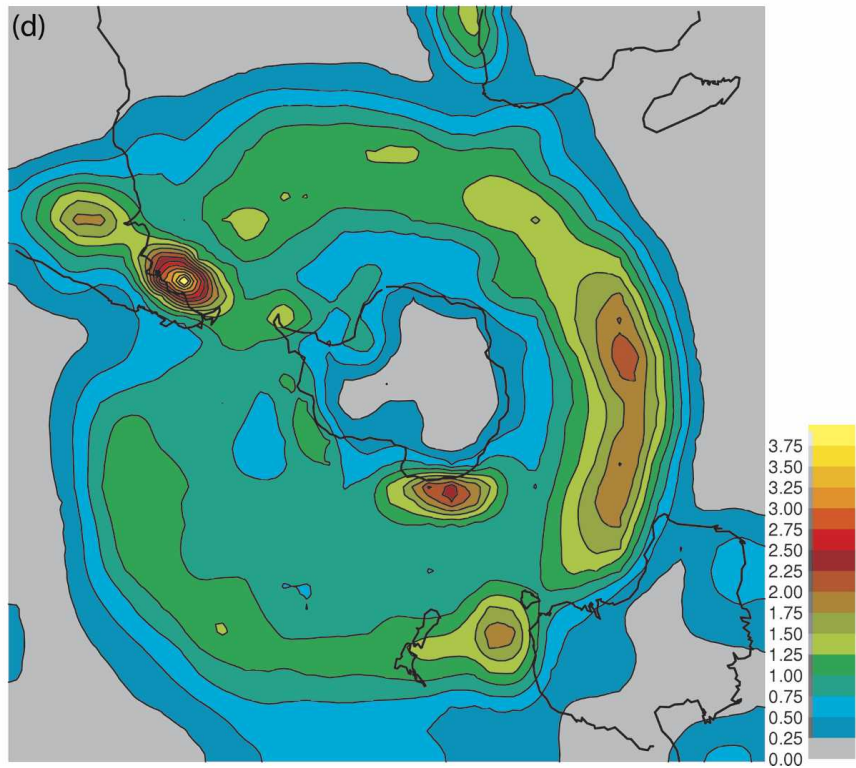

FIG. 4. Same as in Fig. 2, but for SH in JJA.

of tropical and midlatitude SSTs to the structure of the $\mathrm{SH}$ winter storm tracks. For a more detailed account of SH storm track activity in ERA-40 see Hoskins and Hodges (2005).

Figures $4 \mathrm{~b}, \mathrm{~d}$ show the results for the AMIP ECHAM5 integrations averaged over the three realizations. The areas of cyclogenesis are rather similar to that of ERA-40 but some differences can be seen. The area of cyclogenesis is more concentrated in the southern part of Patagonia with the more equatorward maxima being considerably weaker than in ERA-40, possibly consistent with deficiencies in the representation of the winter time split jet structure compared to ERA-40. There is also more genesis in the Indian Ocean sector and east of Tasmania than in ERA-40. As can be seen in Fig. $4 \mathrm{~b}$ the double band of storm tracks exists between Australia and South America in the ECHAM5, but the break through the Tasmania region is less clear than in ERA-40. The intensity of the storms is similar to ERA-40 but less confined in the Western Hemisphere. On the other hand the storms in ECHAM5 are stronger around east Antarctica with a 


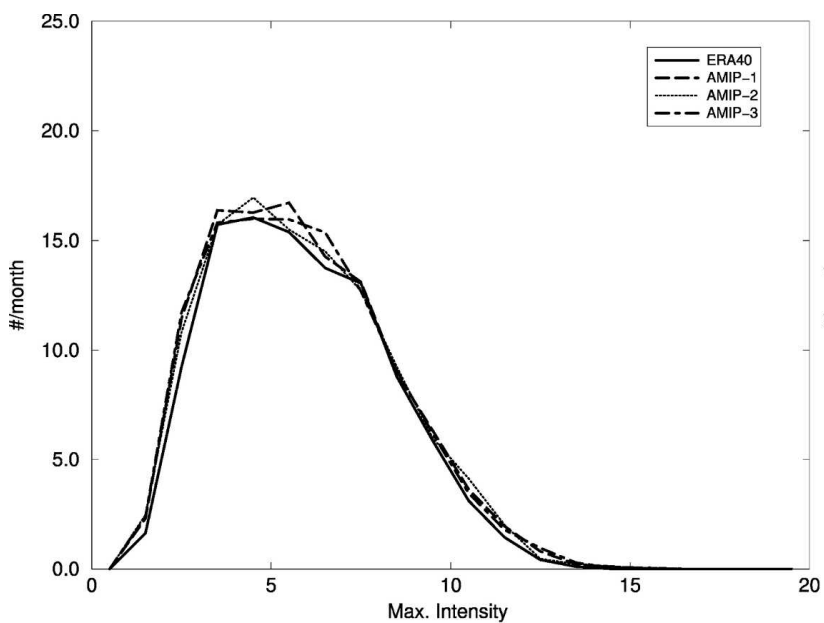

(a)

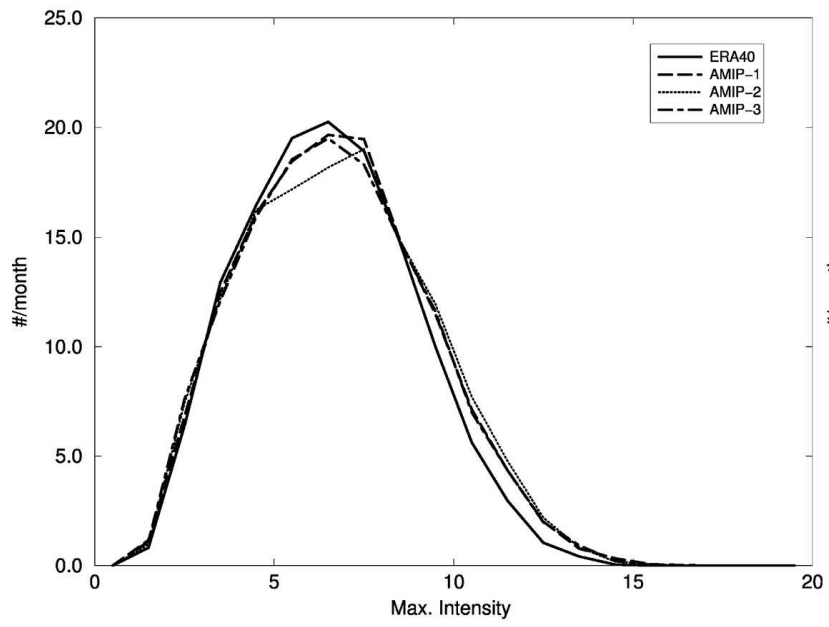

(c)

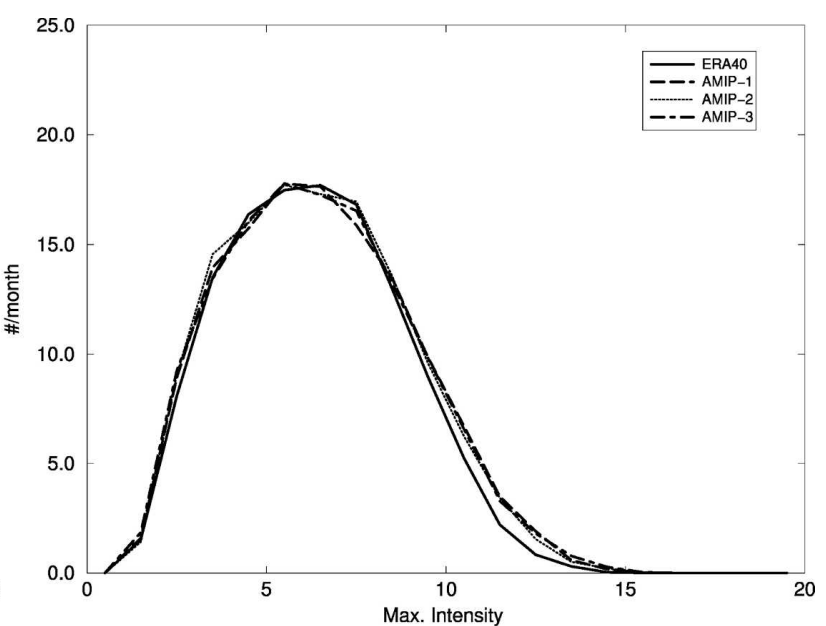

(b)

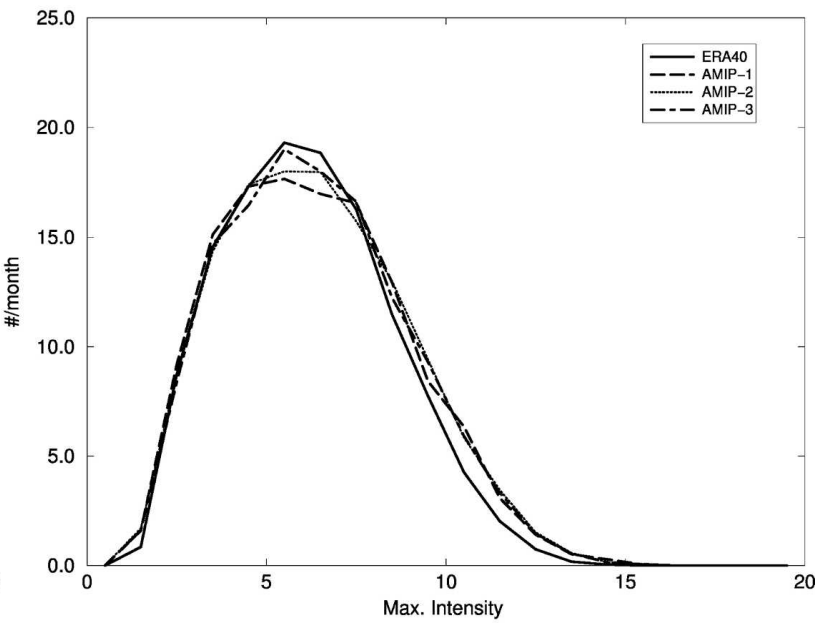

(d)

FIG. 5. Same as in Fig. 3, but for the SH, poleward of $30^{\circ} \mathrm{S}$.

higher density in the Indian Ocean associated with the higher level of genesis there. In Fig. 5 the numbers of individual cyclones per month and for each season, respectively, are displayed as a function of their maximum. Note the great similarity between the three ECHAM5, AMIP integrations, and ERA-40 for all seasons, although ERA-40 has systematically fewer systems in the tails of the distributions than ECHAM5, which is consistent with the spatial statistics previously discussed and probably stems from the differences in the Indian Ocean storm activity. Whilst it is clear that there are more systematic differences between the model and ERA-40 in the SH compared with the NH, overall we still consider the model to be performing reasonably well in the $\mathrm{SH}$.

Since the climate change simulations will be compared with a simulation of the current climate for the period 1961-90, it is interesting to note that comparing with ERA-40 for this period in the SH has some difficulties associated with the change in the observing system in 1979. Before that time the analyzed cyclones for ERA-40 are generally weaker, as can be seen in Fig. 6. However, the ECHAM5 results are more similar to ERA-40 for the later period. As discussed by Bengtsson et al. (2004), this is not due to any climate change but to changes in the observing systems. Before 1979 the observing system of the SH had little satellite observations and included very few upper-air observations so the determination of weather systems by a three-dimensional variational data assimilation (3DVAR) analysis may suffer from a somewhat inconsistent merging of the sparse observations and model information in the data assimilation with a resulting larger dependence on the model. Even in the latter 


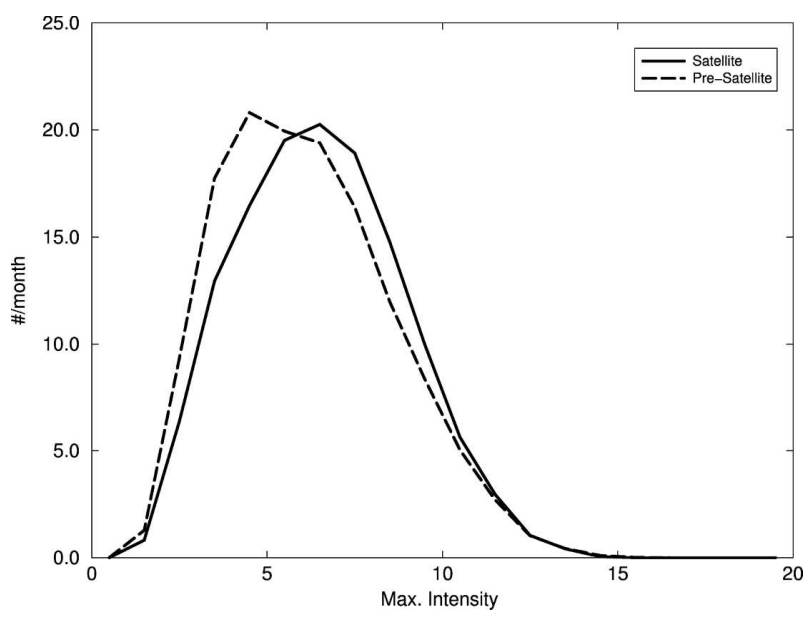

FIG. 6. Distributions of the number of $\xi_{850}$ cyclonic storms per month vs their maximum intensity for ERA-40 in the SH for the periods 1958-78 and 1979-2002. Intensity is in units of $10^{-5} \mathrm{~s}^{-1}$; bin width is $1 \times 10^{-5} \mathrm{~s}^{-1}$.

period the comparison of cyclones between different reanalyses in the SH shows a greater degree of variation compared with those in the $\mathrm{NH}$ (Hodges et al. 2003, 2004).

\section{c. Tropical storm tracks}

For the tropical storm tracks the study is restricted to the $\mathrm{NH}$ active season encompassing the months May through October. Figure 7 shows the storm track density and mean intensity for ERA-40 and the ECHAM5 AMIP integration (averaged over the three ensemble members), respectively. The Atlantic storm track shows systematic differences in both density and intensity in ECHAM5 (Figs. 7b,d) compared with ERA-40 (Figs. $7 \mathrm{a}, \mathrm{c})$, with more and stronger activity over the African continent in ECHAM5 associated with the heat lows that develop in the region of the Hoggar and Airr Mountains, as indicated in the genesis statistics (not shown). There is also a more northerly position of the entrance of the storm track over the Atlantic Ocean in ECHAM5 with fewer systems in the more southerly track than are seen in ERA-40 associated with the main convective band over the Guinea highlands. The fact that there appear to be more storms entering the storm track but that they are weaker in ECHAM5 may indicate the less favorable conditions for storm amplification as the SSTs are lower to the north. The downstream part of the Atlantic storm track also shows differences with an indication of a split in the track in
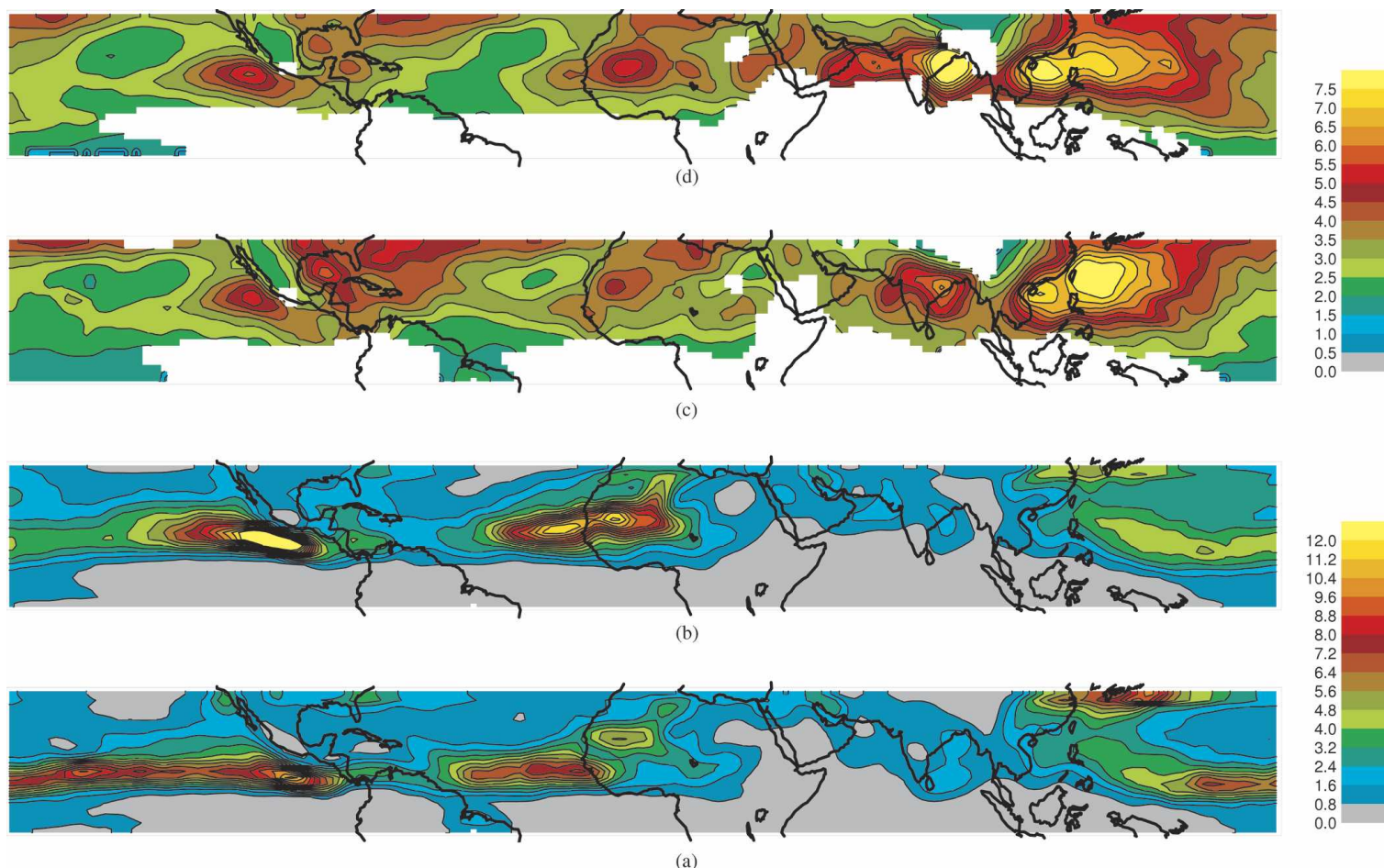

FIG. 7. Statistics for the NH tropical summer time (May-October) easterly wave and tropical cyclone activity in the $\xi_{850}$ field: (a) ERA-40 track density, (b) ECHAM5 AMIP track density, (c) ERA-40 mean intensity, and (d) ECHAM5 AMIP mean intensity. Track density is the number density per month per unit area where the unit is equivalent to a $5^{\circ}$ spherical cap $\left(\sim 10^{6} \mathrm{~km}^{2}\right)$ and the mean intensity is in units of $10^{-5} \mathrm{~s}^{-1}$. AMIP results are averaged over the three realizations. 
ERA-40, with one branch extending to the Venezuela coast and into the eastern Pacific, systems being initiated or reinvigorated on the Venezuela coast (Thorncroft and Hodges 2001), and a hint of the recurving tropical cyclones in the second branch. This then results in a reduction in activity south of Cuba. In ECHAM5 there is no evidence of this split and indeed less evidence of systems reaching the Venezuela coast; the storm track appears broader into the Caribbean with activity shown throughout the Caribbean. This may indicate problems with the steering of the storms in ECHAM5. The mean intensity of systems in ERA-40 (Fig. 7c) also appears higher in this region than in ECHAM5 (Fig. 7d). Results from higher-resolution AMIP integrations (T106 and T159; not shown) indicate that the distributions in the Caribbean appear to improve with resolution, although not over Africa.

The activity in the eastern Pacific is reproduced well in ECHAM5 but shows greater activity than in ERA40, however the mean intensity is in good agreement with ERA-40. The reason for the discrepancy in the level of activity is not clear but may be related to the complex interaction of the Caribbean potential vorticity gradients and the orography of the Sierra Madre Mountains as pointed out by Molinari et al. (1997).

The storms in the central and western Pacific both with respect to position and intensity are generally in good agreement except for a somewhat lower track density in ECHAM5. ECHAM5 also shows a much broader storm track than ERA-40 from the central Pacific; this again may be associated with problems with the steering of the systems or the resolution of the model. Results from the higher-resolution integrations do show some improvement in this respect. The Indian Ocean region systems, though showing a much-reduced level of storm activity in both ERA-40 and ECHAM5 compared with the Atlantic and Pacific, do show the characteristics of monsoon depressions initiating in the Bay of Bengal and the Arabian Sea before traveling inland. The mean intensity of these systems in ECHAM5 is shown to be much larger than in ERA-40, in particular in the Bay of Bengal and along the monsoon trough. It is not clear why this is the case; certainly the situation is not improved in the higher-resolution AMIP integrations.

Figure 8 shows the number of storms as a function of maximum intensity. While the overall number is about the same, there are slight differences in the distribution. There are more weak storms in ERA-40 $(<6 \times$ $10^{-5} \mathrm{~s}^{-1}$ ), but stronger storms in ECHAM5 than in ERA-40 between 6 and $15 \times 10^{-5} \mathrm{~s}^{-1}$. An inspection of the regional distribution of storms (not shown) suggests that these changes are not the same everywhere. In the

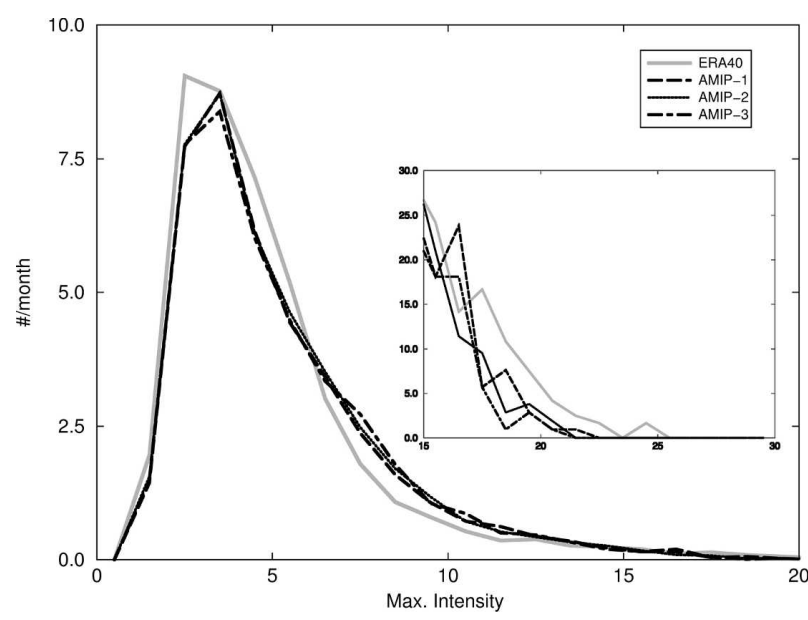

FIG. 8. Distributions of the number of $\xi_{850}$ and cyclonic systems per month vs their maximum intensity for ERA-40 and the three ensemble members of the AMIP ECHAM5 integrations for the Tropics. Systems must be initiated within $0^{\circ}-20^{\circ} \mathrm{N}$, and attain their maximum within $0^{\circ}-35^{\circ} \mathrm{N}$. The inset shows the tails of the distributions scaled to the full season ( 6 months) and for 20 years. Intensities are in units of $10^{-5} \mathrm{~s}^{-1}$; bin width is $1 \times 10^{-5} \mathrm{~s}^{-1}$.

western Pacific the distribution is similar to the global mean, but in the Atlantic the stronger storms $(>6 \times$ $10^{-5} \mathrm{~s}^{-1}$ ) are generally underestimated in the model run. For the rather few very strong storms occurring only once a year or less (see inset of Fig. 8) there are fewer of them in ECHAM5 than in ERA-40.

\section{d. Storm track dependency of ENSO}

To explore the response of the model to the boundary conditions, the impact of ENSO on the storm tracks is explored, using the observed monthly Niño-3 index for the period 1979-2001. The model response to ENSO is calculated by producing composite statistics for the warm and cold phases using the Niño-3 index, normalized and centered, to provide additional weights for the statistical estimation (see the appendix). Figures 9a-d show the difference in the track density between the warm and cold phases of ENSO for ERA-40 and the ECHAM5, (AMIP integrations averaged over the three members) for the $\mathrm{NH}$ and tropical storm tracks. The NH storm track for ERA-40 (Fig. 9a) shows a southerly translation over the United States with the largest reduction around the Great Lakes and the largest increase in a band following the southernmost United States and northeastward over the North Atlantic. The Pacific storm track is enhanced in a band from eastern China eastward over the Pacific to the west coast of the United States and Canada. The ECHAM5 model results (Fig. 9b) are very similar, demonstrating that the response of the model to the 


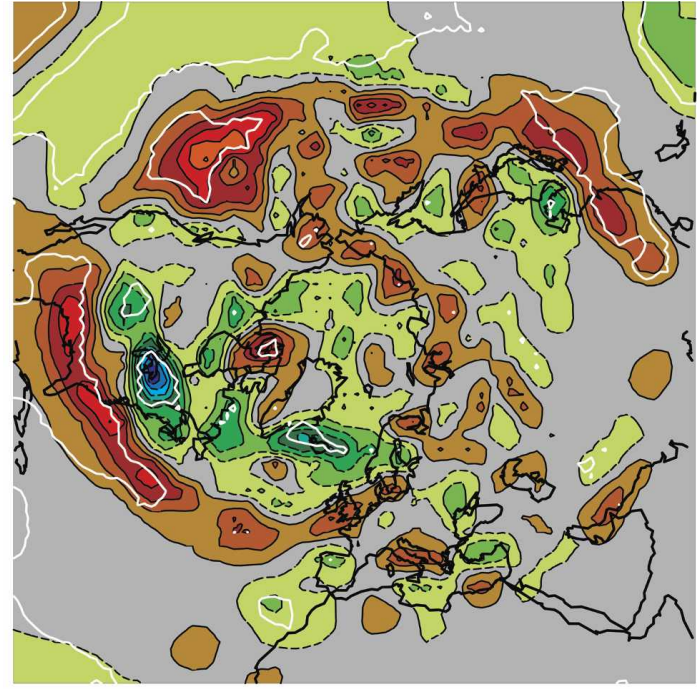

(a)ERA40

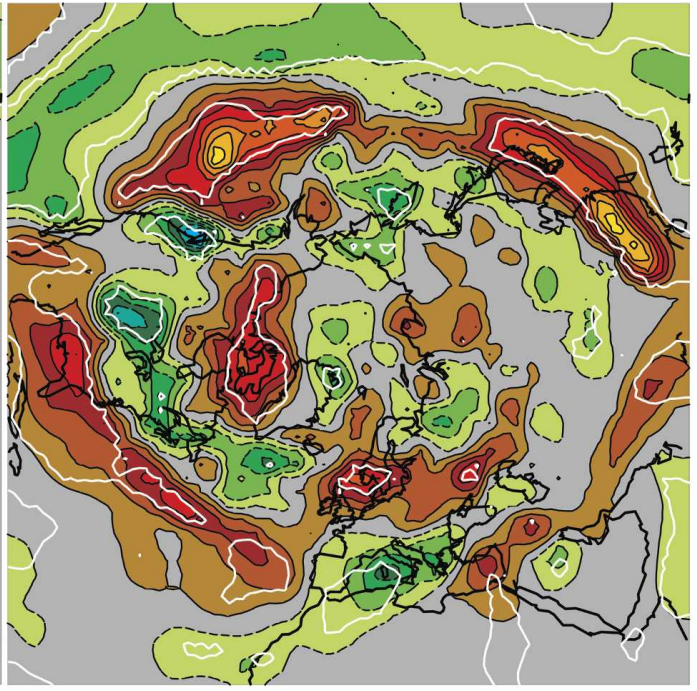

(b)ECHAM5

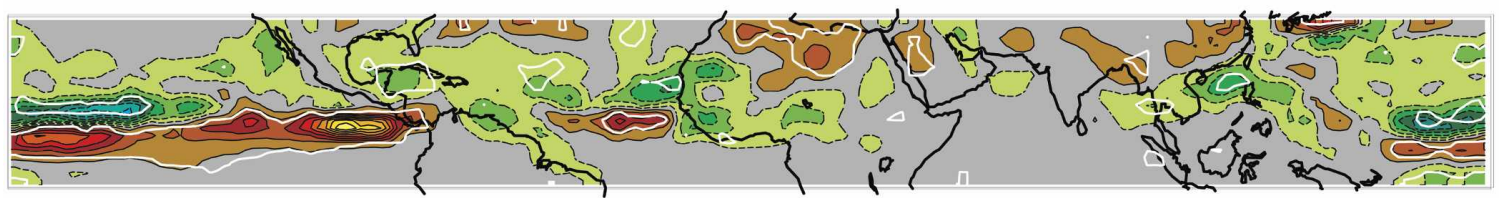

(c)ERA40 TRD

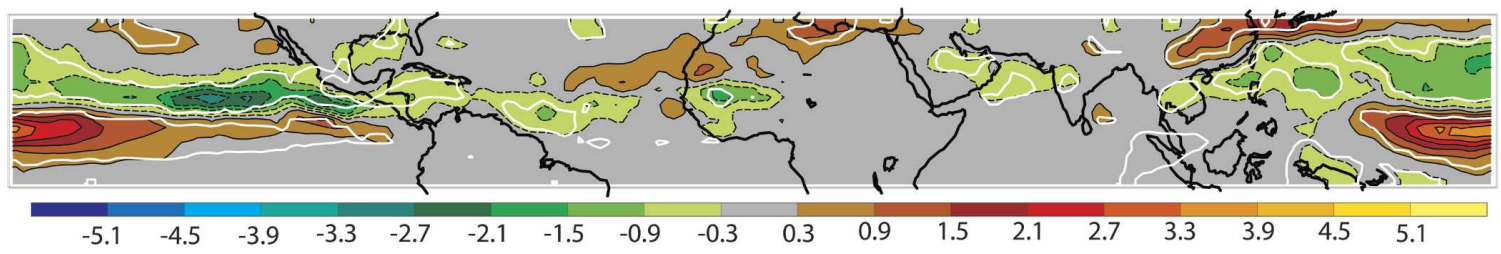

(d)ECHAM5 TRD

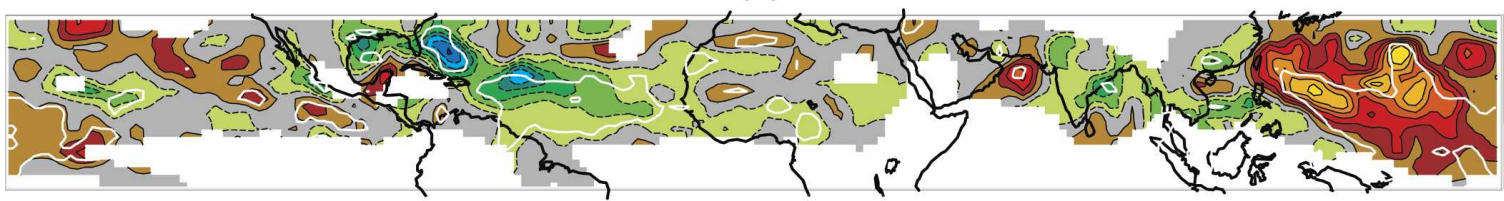

(e)ERA40 STR

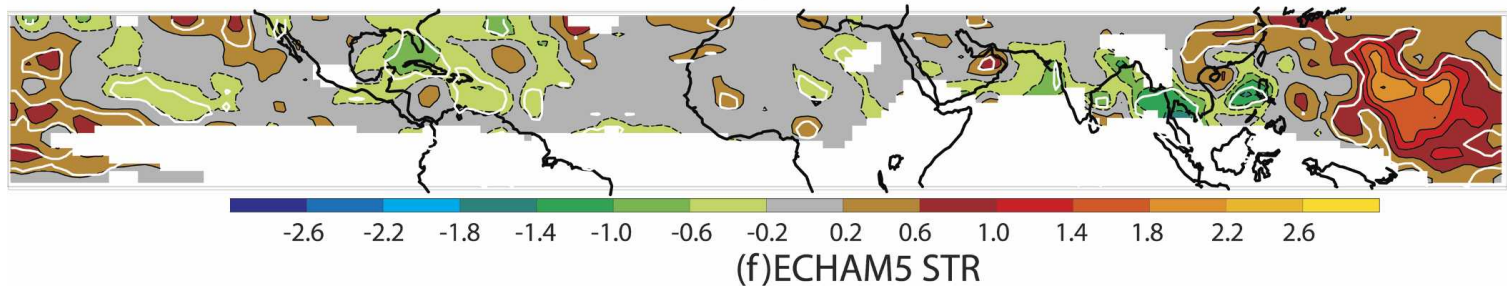

FIG. 9. Response of storm tracks to ENSO and the difference in track density and mean intensities (warm - cold) for $\xi_{850}$ cyclonic systems: (a) NH, DJF, ERA-40 track density; (b) NH, DJF, ECHAM5, AMIP track density; (c) ERA-40 Tropics, May-October track density; (d) ECHAM5, AMIP Tropics, May-October track density; (e) ERA-40 tropical, May-October mean intensity; and (f) ECHAM5, AMIP Tropics, May-October mean intensity. Density differences are the number densities per month per unit area where the unit area is equivalent to a $5^{\circ}$ spherical cap $\left(\sim 10^{6} \mathrm{~km}^{2}\right)$. Mean intensity differences are in units of $10^{-5} \mathrm{~s}^{-1}$. AMIP results are averaged over the three realizations before differencing. The white lines indicate regions where the $p$ values are less than $5 \%$. See text for further details. 
ENSO SSTs is quite realistic, as also shown by van Oldenborgh et al. (2005), but the model response is generally stronger. The three AMIP experiments (not shown) are very similar and more similar to each other than any of them to ERA-40, suggesting that the strength of the ENSO response is mainly a model bias. The Pacific response is slightly stronger but with a similar pattern, and it reflects the bias ECHAM5 has over southern China. The Atlantic storm track change in the model run is similar to ERA-40 but with a stronger response over both northern and southern Europe (this can be seen in all AMIP runs). The intensity differences (not shown) are generally quite weak and noisy for ERA-40 apart from the northeastern Pacific and southern United States where larger differences are found $\left(\sim 1.0 \times 10^{-5} \mathrm{~s}^{-1}\right)$ coincident with the track density changes. For ECHAM5 more coherent differences are seen in a similar pattern to those for the track density but with absolute values of typically $\sim 0.5-1.0 \times$ $10^{-5} \mathrm{~s}^{-1}$.

In the Tropics in general the response of the tropical storm tracks to ENSO SST anomalies also shows relatively good correspondence between ERA-40 (Fig. 9c) and ECHAM5 (Fig. 9d), with a shift in the east and west Pacific storm track equatorward for both. In the Atlantic, ERA-40 shows a somewhat larger and more coherent reduction in the storm track activity when compared with ECHAM5. However, the Atlantic changes are very weak. In terms of the intensity differences, shown in Figs. 9e,f, these also show some interesting coherent patterns of change. In particular ERA40 shows a general weakening of the intensities in the Atlantic with an increase in intensity in the western Pacific. These intensity differences are generally larger than those seen in the $\mathrm{NH}$ winter extratropics. For ECHAM5 this pattern of change is also generally well reproduced, apart from the changes in the Atlantic, which appear to be a lot weaker than in ERA-40.

\section{e. Conclusions}

The general result from this part of the study is that the performance of the ECHAM5 atmospheric model compares very favorably with the ERA-40 reanalyses with respect to both extratropical and tropical synopticscale weather systems and their variability with respect to the boundary forcing; this is particularly so for the $\mathrm{NH}$. Systematic differences in the SH and Tropics require further study to determine their causes, though we believe even here that ECHAM5 is performing relatively well. A caveat of the comparison comes from the fact that differences also occur between different reanalyses, in particular in the $\mathrm{SH}$ and Tropics (Hodges et al. 2003, 2004), and can be as large or larger than the differences between ERA-40 and ECHAM5. Compared to ERA-40, for example, the National Centers for Environmental Prediction (NCEP) reanalyses underestimate the number of storms-in particular the more intense ones. This situation arises from how different reanalyses make use of sparse data and even how dense data are assimilated, for example, satellite data in the SH. The fact that ECHAM5 compares so favorably with ERA-40, in particular for the intensity distributions, could be considered to be related to the fact that the ECHAM5 model uses the same dynamical core as ERA-40. However, ECHAM5 differs significantly from ERA-40 in the parameterizations that are used. ERA40 essentially uses an operational model tuned for operational purposes, whilst ECHAM5 is designed for climate simulation. The agreement could also be fortuitous to some extent, although similar results are obtained from the analysis of higher-resolution AMIP integrations with the same model. Consequently we believe the ERA-40 reanalyses to provide the best current view of the atmosphere over the AMIP period and hence the best validation data for ECHAM5.

\section{How will climate change affect the storm tracks?}

As described in section 2 we investigate here the SRES scenario A1B and compare two 30-yr periods of 1961-90 (20C), which represents the present climate, and 2071-2100 (21C), which represents a future climate. For a general reference of this climate change experiment see Muller and Roeckner (2006). Here we analyze and discuss changes in the storm tracks between the two periods. For the extratropics in both hemispheres the 20C run agrees with the ECHAM5 AMIP runs in most details (not shown). There are somewhat larger differences in the Tropics (not shown) as the SST distribution of the coupled model differs from the prescribed SSTs used in the AMIP integrations. Such differences are presumably unavoidable as the observed climate of a $30-\mathrm{yr}$ period is only one of many possible realizations. Furthermore, a climate change experiment is essentially a perturbation study and therefore the discussion will concentrate on the differences between $20 \mathrm{C}$ and $21 \mathrm{C}$.

\section{a. NH extratropics}

Figure 10 shows the difference in the cyclone track statistics (averaged over the three members of 20C and 21C) for $\xi_{850}$. There is a general poleward translation of the storm tracks during the boreal winter (DJF; Fig. 10a) in both ocean basins. In particular there is a reduction in the number of systems in the southern parts 

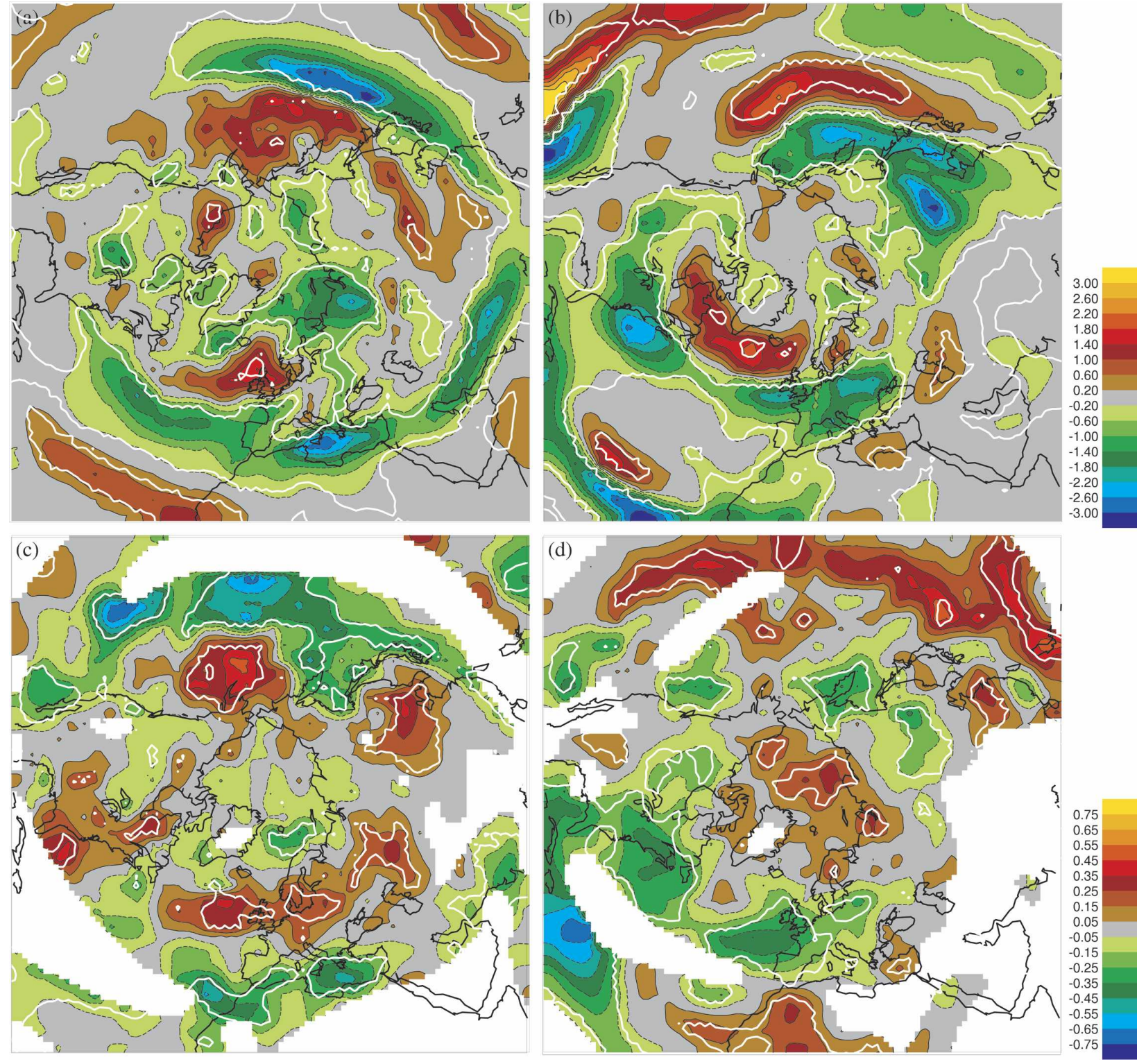

FIG. 10. Difference in NH cyclone track statistics for $\xi_{850}$, between the $21 \mathrm{C}$ and 20C periods $(21 \mathrm{C}-20 \mathrm{C})$ averaged over the three ensemble members before differencing: (a) DJF track density, (b) JJA track density, (c) DJF mean intensity, and (d) JJA, mean intensity. Track density differences are the number density per month per unit area, where the unit area is equivalent to a $5^{\circ}$ spherical cap $\left(\sim 10^{6} \mathrm{~km}^{2}\right)$. Mean intensity differences are in units of $10^{5} \mathrm{~s}^{-1}$. Mean intensity differences are only plotted where the track density is greater than 1 per month per unit area. The white lines indicate regions where the $p$ values are less than $5 \%$. See text for further details.

of the storm tracks, which in the Atlantic extends into the Mediterranean and through the Middle East. There is also a reduction in activity in the Siberian storm track. In a region covering the British Isles and the area to the north and west there is a distinct increase in the storm track density. This is seen in the differences between all ensemble members. The mean intensities (Fig. 10c) show a weakening through the Mediterranean but an increase where the increase in track density occurs in the Atlantic, which extends into western Eu- rope. There is also a general weakening of the storm tracks in the northernmost part of the Atlantic Ocean and the Norwegian Sea, both as a reduction in storm numbers and their intensities. In the Pacific there is a general weakening along the southern part of the storm track as well as at the start of the storm track and over Japan, whilst there is an increase in the northeastern Pacific. Since the mean intensity differences appear to mostly coincide with the changes in the number of storms, this would appear to indicate that it is the num- 
ber rather than an increase in the intensity that explains many of these changes (see later). Spring (MAM) and autumn (SON) changes (not shown) resemble those of winter, but the summer (JJA) is different. Figure 10b shows the JJA track density differences, which show a more northerly pattern of change over North America and the North Atlantic and which also appear as a shift poleward. In the Pacific the change appears more as an equatorward shift. As in the DJF period, the changes in mean intensity (Fig. 10d) show changes in correspondence with the changes in the number of storms; this is particularly apparent over North America and the North Atlantic extending into western Europe, with a general reduction in the storm intensities. In the Arctic there is an overall increase in the mean storm intensity.

Figure 11 shows the distribution of storms as a function of their maximum intensity for DJF and JJA, respectively. The distribution is very similar for both the $20 \mathrm{C}$ and $21 \mathrm{C}$ climates but with a slightly smaller number of storms of intermediate intensity in the $21 \mathrm{C}$. The number of storms at the very high end of the distributions (Fig. 11, insets) shows that there are no indications of an increase in more intense storms for 21C. A detailed inspection shows that the differences between individual members for each climate period vary as much or as little as the differences between members from different climate periods.

Focusing on the European area, Fig. 12 shows the distribution of maximum intensities for the area covering the eastern North Atlantic including the British Isles $\left(50^{\circ}-65^{\circ} \mathrm{N}, 0^{\circ}-40^{\circ} \mathrm{W}\right)$ and the Mediterranean region $\left(30^{\circ}-45^{\circ} \mathrm{N}, 0^{\circ}-40^{\circ} \mathrm{E}\right)$. The North Atlantic region shows a systematic increase in the stronger storms $\left(>10 \times 10^{-5} \mathrm{~s}^{-1}\right)$; this behavior extends into the northern European region $\left(50^{\circ}-65^{\circ} \mathrm{N}, 0^{\circ}-30^{\circ} \mathrm{E}\right.$; not shown). The Mediterranean region on the other hand shows an overall reduction in the number of storms with maximum intensity larger than $4 \times 10^{-5} \mathrm{sec}^{-1}$ (Mediterranean storms are generally smaller and weaker than Atlantic storms). An inspection of all combinations of changes between the three experiments of $21 \mathrm{C}$ and $20 \mathrm{C}$ indicate that these changes are robust as they occur in all combinations of differences.

\section{b. SH extratropics}

Figure 13 shows the results for the $\mathrm{SH}$, for the austral summer (DJF) and winter (JJA). There is a marked poleward translation of the storm tracks for all seasons. This result is robust, as it is clearly seen in all combinations of differences between $21 \mathrm{C}$ and $20 \mathrm{C}$ and has been seen in previous studies, for example, Fyfe (2003) and Kushner et al. (2001). The greatest reduction in the number of storms occurs around $40^{\circ} \mathrm{S}$ during the austral

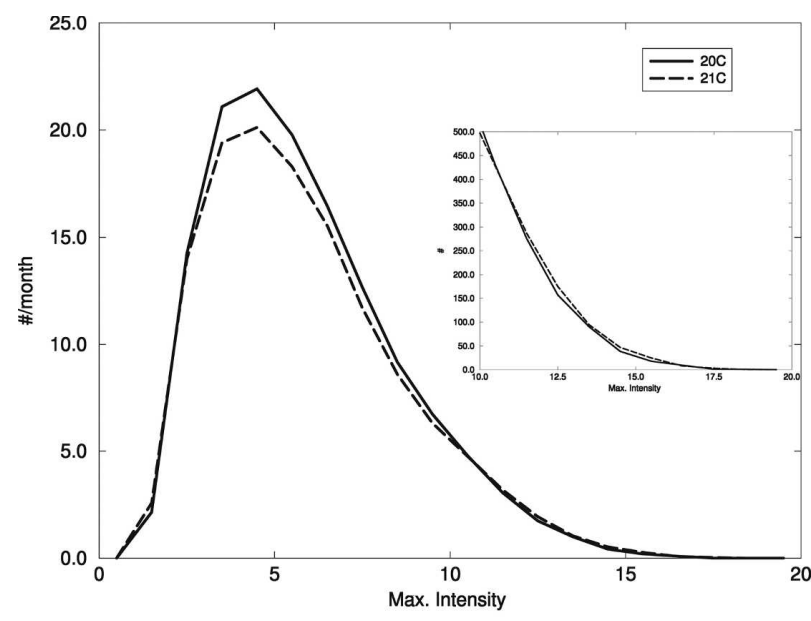

(a)

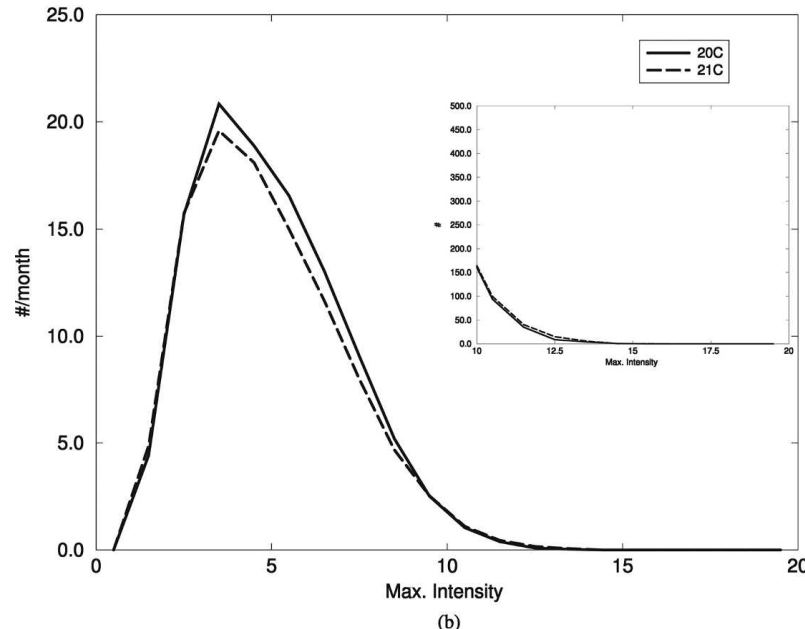

FIG. 11. NH distributions of number of $\xi_{850}$ cyclonic systems per month vs their maximum intensity for $20 \mathrm{C}$ and $21 \mathrm{C}$ averaged over the three ensemble members for $30^{\circ}-90^{\circ} \mathrm{N}$ : (a) DJF and (b) JJA. The insets show the tails of the distributions scaled to the full season (3 months) and for $30 \mathrm{yr}$. Intensities are in units of $10^{-5} \mathrm{~s}^{-1}$; bin width is $1 \times 10^{-5} \mathrm{~s}^{-1}$.

winter over southern Australia and the northern part of New Zealand. In the summer the reduction in activity occurs around $50^{\circ} \mathrm{S}$ with a corresponding increase in activity around $60^{\circ} \mathrm{S}$ (Kushner et al. 2001). In addition to the changes in the geographical distribution of storms the changes in the mean intensities indicate a general increase in intensity in the winter (JJA) for 21C in the regions where there is an increase in activity, whilst during the summer period (DJF) there is a general weakening of the storm intensities. As in the Mediterranean region during the $\mathrm{NH}$ boreal winter, where there is also a reduction in storm activity for $21 \mathrm{C}$, it is expected that a consequence of these changes in the storm tracks in the $\mathrm{SH}$ will be a reduction in precipitation in these regions, as most of the precipitation is 


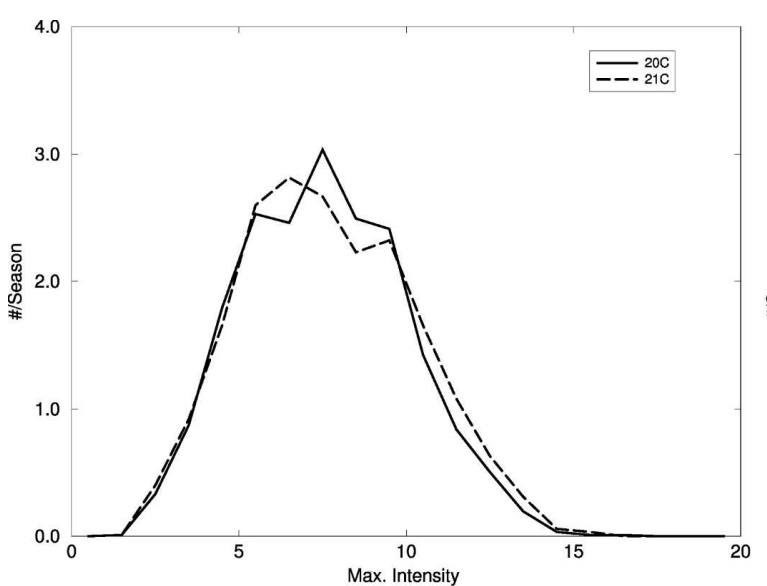

(a)

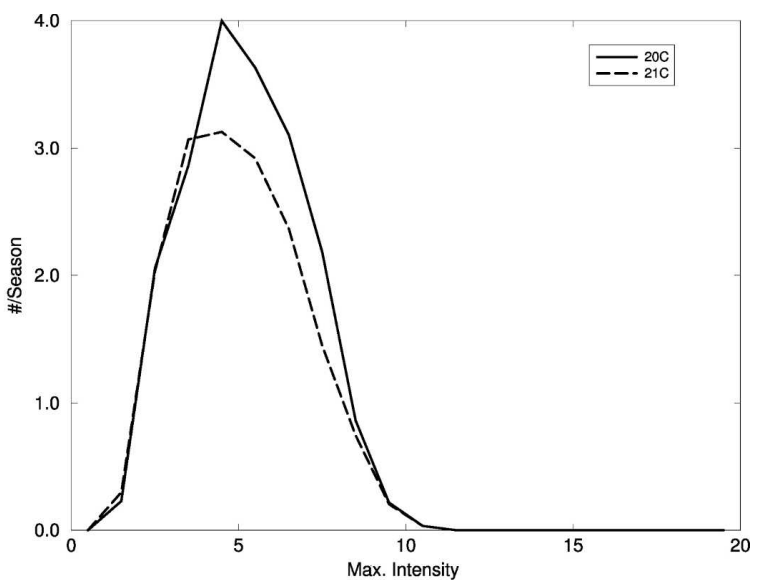

(b)

FIG. 12. NH winter (DJF) distributions of number of $\xi_{850}$ cyclonic systems per season vs their maximum intensity for $20 \mathrm{C}$ and $21 \mathrm{C}$ averaged over the three ensemble members for (a) the eastern Atlantic $\left(50^{\circ}-65^{\circ} \mathrm{N}, 0^{\circ}-40^{\circ} \mathrm{W}\right)$ and (b) the Mediterranean $\left(30^{\circ}-45^{\circ} \mathrm{N}\right.$, $0^{\circ}-40^{\circ} \mathrm{E}$ ). Intensities are in units of $10^{-5} \mathrm{~s}^{-1}$; bin width is $1 \times 10^{-5} \mathrm{~s}^{-1}$.

associated with transient depressions. Many of these changes are mirrored in the upper troposphere; in particular examination of the track density for $\xi_{250}$ (not shown) indicates that the split jet (Hoskins and Hodges 2005 ) occurs for all seasons for 21C, whereas for 20C it is most prevalent during the winter (JJA). There are also considerable changes to the configuration of the split jet even in winter, with a weakening in the level of activity for $21 \mathrm{C}$ compared with $20 \mathrm{C}$. These changes are possibly in response to changes in the tropical convection with a resulting change in the generation of Rossby waves (Inatsu and Hoskins 2004), which act to control the structure of the upper-tropospheric jets.

Figure 14 shows the number of storm as a function of their maximum intensity for $20 \mathrm{C}$ and $21 \mathrm{C}$, respectively, for summer (DJF) and winter (JJA). There is a general reduction in the number of weaker storms in $21 \mathrm{C}$ for both winter and summer but an increase in the number of stronger storms, larger than $10 \times 10^{-5} \mathrm{sec}^{-1}$, during the winter period. This change is robust and is valid for all members of the ensemble. We suggest that the cause is the more poleward position in $21 \mathrm{C}$ of the storm tracks providing easier access to cold air masses from Antarctica that is likely to increase the available potential energy for storm development. The change is most marked during the austral winter.

\section{c. Tropical changes}

The changes in the tropical storm tracks are pronounced and occur in all tropical regions, although we here restrict the presentation to the most active period of the NH from May through October. Figure 15 shows the track density and mean intensity for this period.
This shows that there is a general reduction in activity in the Atlantic storm track as well as a general reduction in the amplitude of the storms, in particular in the main development region (MDR) for tropical cyclones. In the eastern Pacific there is a marked equatorward translation of the storm track with a general enhancement extending well into the central Pacific. In the central Pacific there is also a reduction in the number of storms with an equatorward translation. There is also a large change in the intensity of systems over western Africa. Perhaps the most negligible changes in the distribution of storms occurs in the Indian Ocean region and India, though the density of storms is already small in both $20 \mathrm{C}$ and $21 \mathrm{C}$ compared with the Atlantic and Pacific. However, there is some indication of an enhancement of the intensities of the monsoon depressions in the monsoon trough over India.

Figure 16 shows the number of storms as a function of the maximum intensity for the whole Tropics $\left(35^{\circ} \mathrm{N}\right.$, $0^{\circ}$ ) for $20 \mathrm{C}$ and $21 \mathrm{C}$ (Fig. 16a), and for selected regions. There are only minor changes in the overall distribution of tropical storms except for a slight reduction in the storms of medium intensity for the whole Tropics, and there are no changes in the number of extreme storms throughout the Tropics. However, there are regional variations as indicated by the spatial statistics and in Figs. 16b-d. The Atlantic storms are reduced in number, in particular the stronger ones, while the storms in the eastern Pacific are virtually unchanged though there is some indication of fewer extreme storms. In the western Pacific there is little change. It is interesting to note that the change in SST by between $2^{\circ}$ and $3^{\circ} \mathrm{C}$ has not had any influence on the numbers and intensities of 

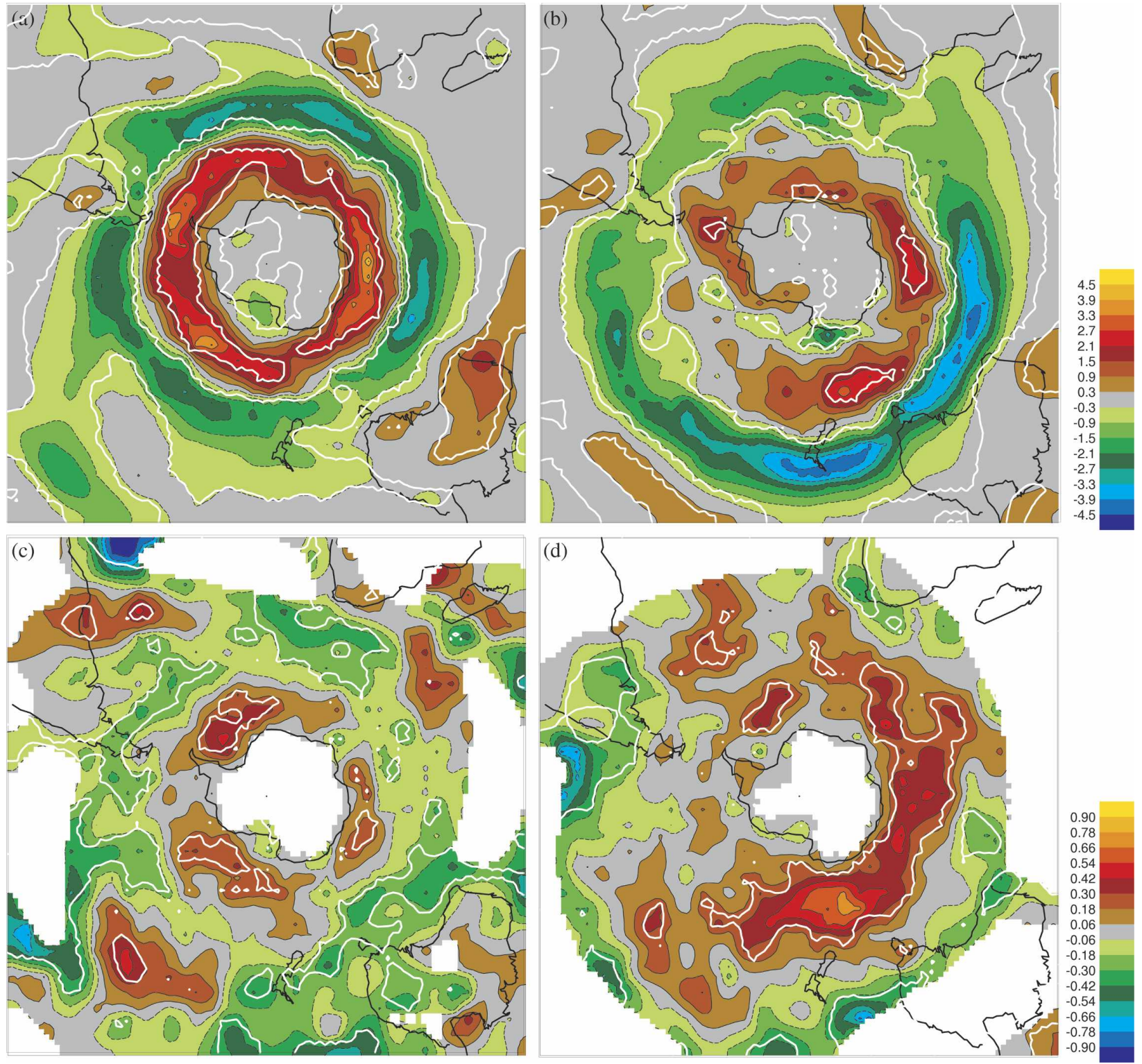

FIG. 13. Same as in Fig. 10, but for SH.

the more powerful tropical storms. The geographical changes in the storm tracks have some similarity to what occurs during El Niño events (Fig. 9c). This may also be expected as the coupled models predict a larger warming in the eastern tropical Pacific, creating a pattern that bears some resemblance to a warm ENSO event. As can be seen in Fig. 9c, the change in the tropical storm tracks goes in the same direction.

\section{Discussion and conclusions}

This study has concentrated on the evaluation of tropospheric storm tracks at $850 \mathrm{hPa}$ using the local rela- tive vorticity as a suitable measure. The local surface pressure minimum could equally well have been used, but the local vorticity extrema around the top of the boundary layer are considered a more representative quantity for the transient cyclones and anticyclones. In fact a similar study has been performed using MSLP and qualitatively similar results were obtained. In general the ECHAM5 model reproduces the extratropical storm tracks in surprisingly good agreement with the analyzed data from ERA-40, in particular in the NH. It is also capable of broadly reproducing the $\mathrm{NH}$ storm track response to ENSO, though with a somewhat stronger signal than seen in ERA-40 associated with a 


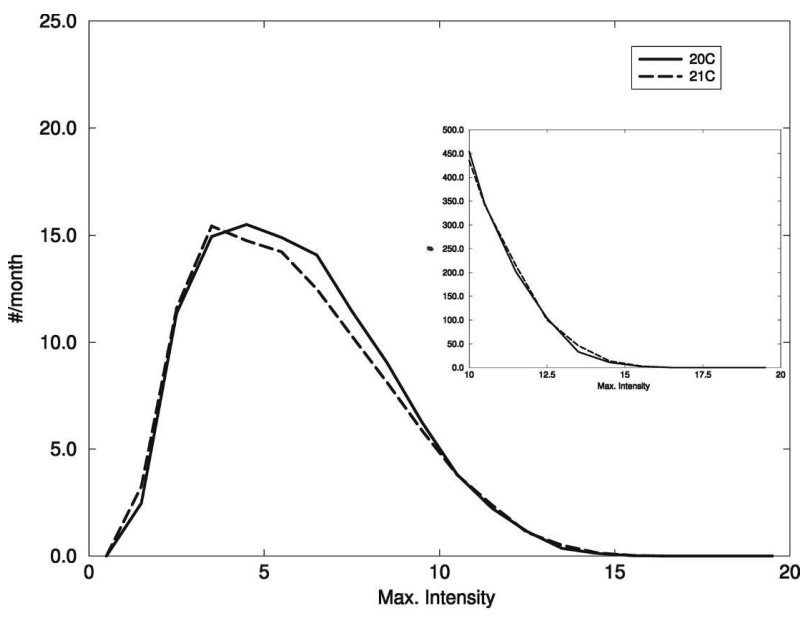

(a)

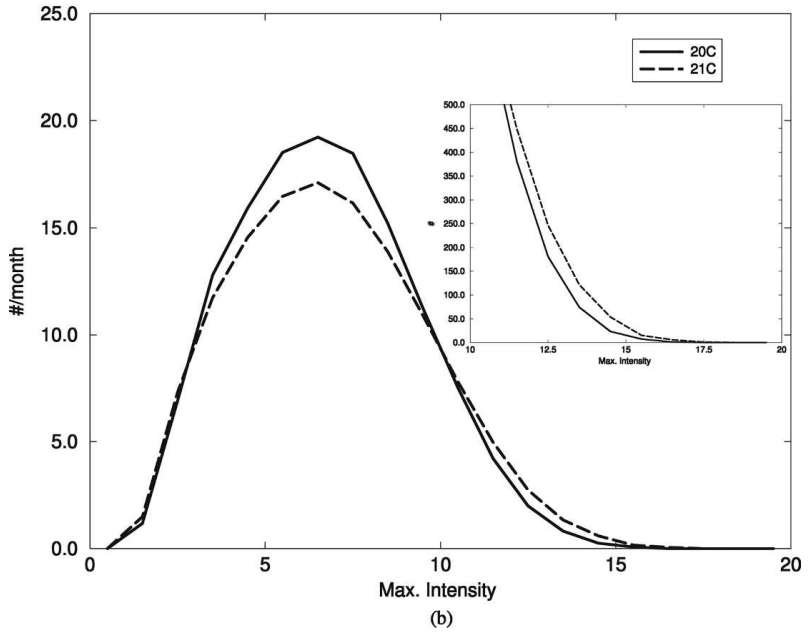

FIG. 14. Same as in Fig. 11, but for SH.

larger Niño-3 amplitude. ECHAM5 is also able to reproduce the statistical distribution of the number of storms as a function of their maximum intensity in surprisingly good agreement with ERA-40 on hemispheric regions. The number of storms as a function of the mean intensity over the lifetime of the storm is also found to produce very similar distributions, albeit shifted to lower intensity values. It is particularly interesting to note that the agreement between model results and ERA-40 is better when satellite observations where available for the $\mathrm{SH}$, that is, after 1979, than before that year. Before 1979 the maximum intensity of the SH storms in ERA-40 was less than after 1979. This suggests that ERA-40 has a systematic bias in the presatellite period, presumably due to the lack of upper-air observations before 1979. Bengtsson et al. (2004) did establish that ERA-40 underestimates the tropospheric kinetic energy in the SH prior to 1979. The tropical validation of ECHAM5 also provides encouraging re- sults, albeit with larger systematic differences from ERA-40 than seen in the extratropics. This includes the ENSO response of the tropical storm track.

In agreement with Geng and Sugi (2003) there appears to be an overall reduction in the numbers of storms between $21 \mathrm{C}$ and $20 \mathrm{C}$ for the $\mathrm{NH}$ (DJF), SH (JJA), and Tropics by $4 \%, 6 \%$, and $6 \%$, respectively (Table 1). For the more intense storms $\left(>8 \times 10^{-5} \mathrm{~s}^{-1}\right)$ the reduction is less, and in fact in the $\mathrm{SH}$ there is a small increase of $3 \%$. However, the increase in the numbers of stronger storms in the SH only occurs during the winter season (Fig. 14) and not during the summer season, as in Geng and Sugi (2003). There are small differences between the three climate change ensemble members, but the differences between the members are as large as the changes between the twentieth and twenty-first century. However, inspection of the geographical statistical distribution of storms indicates some interesting changes. In the SH there is a systematic poleward translation of the storm tracks by some 5 degrees. The cause of this in not clear but could be related to a slight poleward transition of the maximum SST gradient (Fig. 17) supporting the results from Inatsu et al. (2002) using experiments with an aquaplanet model. We intend to repeat these experiments with the ECHAM5 model to be reported later. The result is robust as all nine combinations of differences between the climate change experiments $(21 \mathrm{C}-20 \mathrm{C})$ show similar storm track changes. In the North Atlantic there is an indication of a similar poleward movement but with some deviation over the eastern Atlantic and with an overall increase in a band from the U.S. east coast toward the British Isles and southern Scandinavia. There is a major weakening of the storm track over the Mediterranean and its extension eastward. The climate change experiments indicate a maximum SST warming in the eastern Pacific, reminiscent of an El Niño-like condition (see Fig. 9). We have also examined the ENSO variability in the climate change runs. The statistical SST time variability in the coupled model is similar to observations, but the amplitude in Niño-3 is some $50 \%$ higher, giving rise to a larger atmospheric response. There is no difference in the SST variability between $20 \mathrm{C}$ and $21 \mathrm{C}$ so the warming trend in the eastern Pacific in the twenty-first century is underlying the ENSO variability of the model.

It is suggested that the change in the storm distribution is mainly related to changes in the SST patterns although, as discussed by Held (1993), climate change due to increased greenhouse gas concentration in the atmosphere is expected to lead to a number of changes that may effect the general circulation of the atmosphere. Model experiments (Zhang and Wang 1997; 

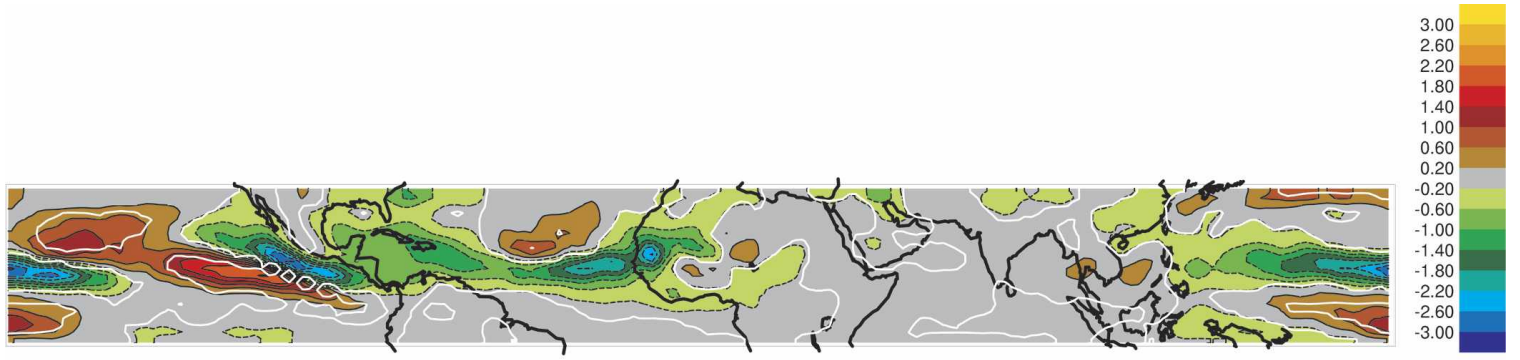

(a)
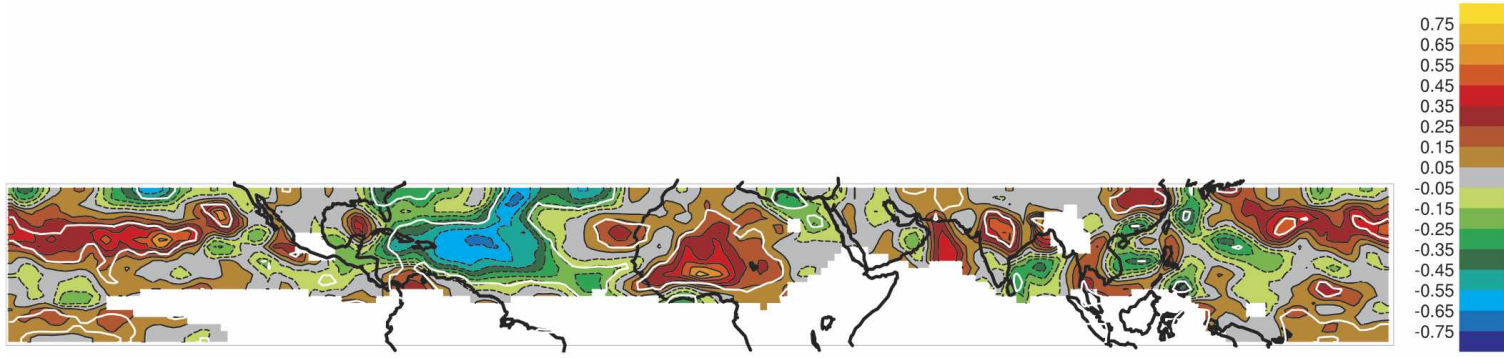

(b)

FIG. 15. Difference in tropical easterly wave and cyclone statistics for $\xi_{850}$, between the 21C and 20C periods (21C - 20C), averaged over the three ensemble members before differencing: (a) track density and (b) mean intensity. Track density differences are the number density per month per unit area, where the unit area is equivalent to a $5^{\circ}$ spherical cap $\left(\sim 10^{6} \mathrm{~km}^{2}\right)$. Mean intensity differences are in units of $10^{-5} \mathrm{~s}^{-1}$. Mean intensity differences are only plotted where the track density is greater than 0.5 per month per unit area. The white lines indicate regions where the $p$ values are less than $5 \%$. See text for further details.

Geng and Sugi 2003) support the results of the coupled ECHAM5 model used here, suggesting a decreased meridional gradient in the lower troposphere and an increased gradient in the upper troposphere. The effect of this implies a more stable stratification at low latitudes and less stable vertical stratification at higher latitudes. This could contribute to less favorable conditions for tropical eddies as suggested by Bengtsson et al. (1996), thus counteracting the higher sea surface temperatures. The reduced stability at higher latitudes could also counteract the reduced meridional gradient in the lower troposphere. The amount of water vapor also increases, broadly following the ClausiusClapeyron relation. The increased amount of water vapor in the atmosphere would mean more efficient transport of heat to higher latitudes, thus requiring less intense vortices as the needed transport can be handled with less energetic eddies.

Inatsu et al. (2002) have investigated the tropical and extratropical SST effects on midlatitude storm tracks. Using an aquaplanet model experiment, they found that the tropical SST forcing generates large extratropical stationary eddies that modulate the storm track distribution. The most straightforward mechanism for explaining the midlatitude equilibrium response is Rossby wave propagation forced by convective heating anomalies that develop locally in response to the SST anomalies (Egger 1977; Hoskins and Karoly 1981; Schneider et al. 2003; Inatsu and Hoskins 2004). A zonal enhancement of extratropical SST gradients generates little stationary eddies but leads to large zonal variations in the storm track (Inatsu et al. 2002; Inatsu and Hoskins 2004). In both cases Inatsu et al. (2002) found that vertical wind shear or baroclinicity in the lower troposphere is closely related to the growth of baroclinic disturbances and the development of upperlevel storm tracks.

It follows from this that any possible change in the storm tracks is a complex process. Any regional SST anomalies are likely to influence the storm tracks in a systematic way. Second, as we have noted in this paper (and has been highlighted by others, e.g., Inatsu and Hoskins 2004) orographic obstacles are crucial for the generation of storm tracks, hence any change in the position of the jet streams may affect the orographic influence; this is most clearly seen in the SH. We suggest that a contributing factor in the poleward translation of the storm track in the SH is due to a movement of the maximum zonal SST gradient poleward as the warming at low and middle latitudes is higher than at higher latitudes. The changes in the zonal SST gradient is shown in Fig. 17 together with the corresponding change in the zonal track density at 850 and $250 \mathrm{hPa}$; larger changes might be expected in particular regions 


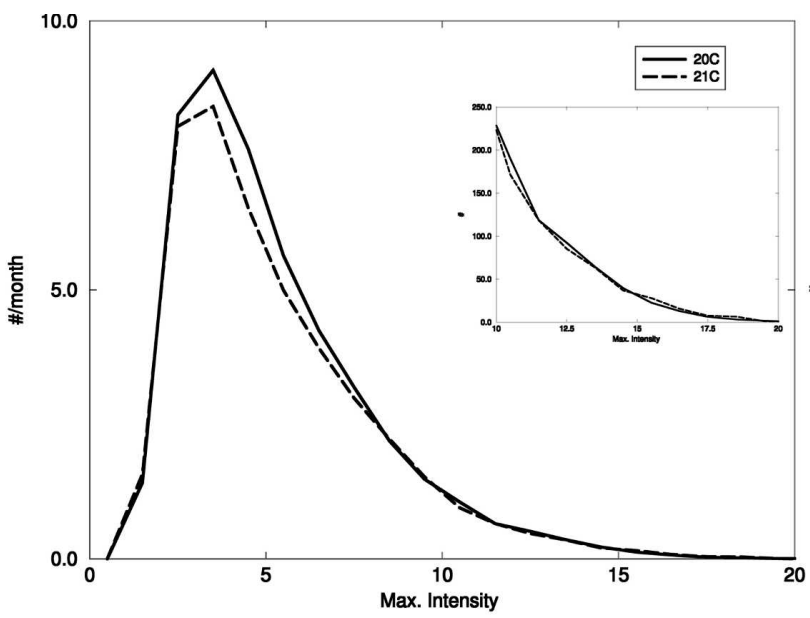

(a)

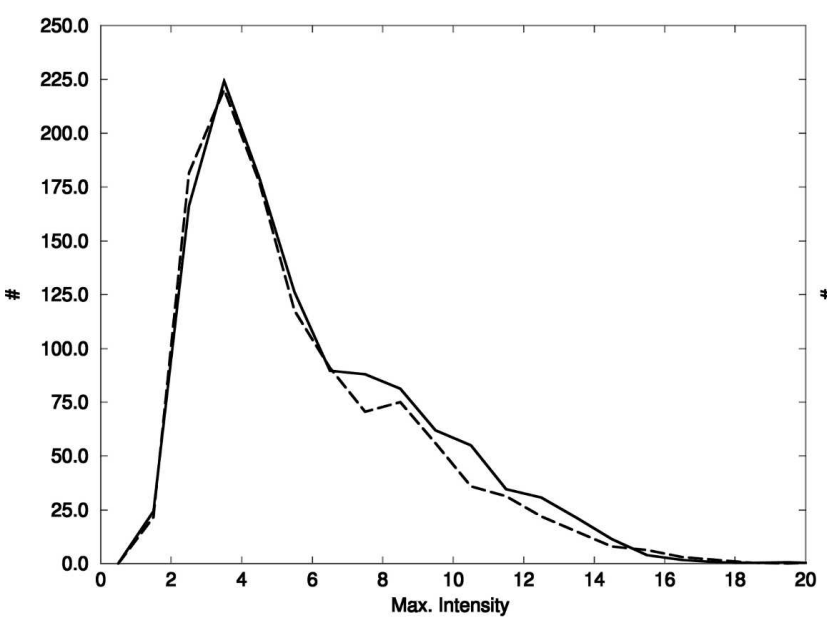

(c)

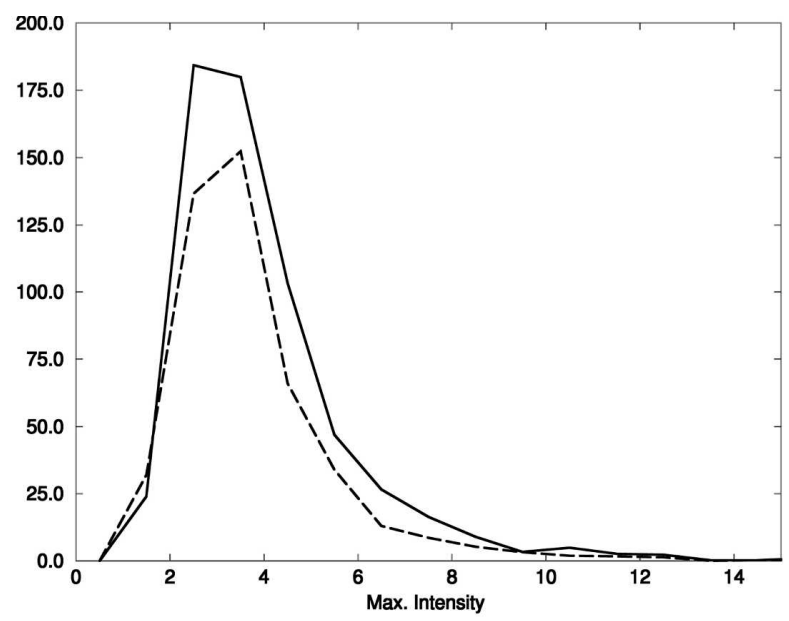

(b)

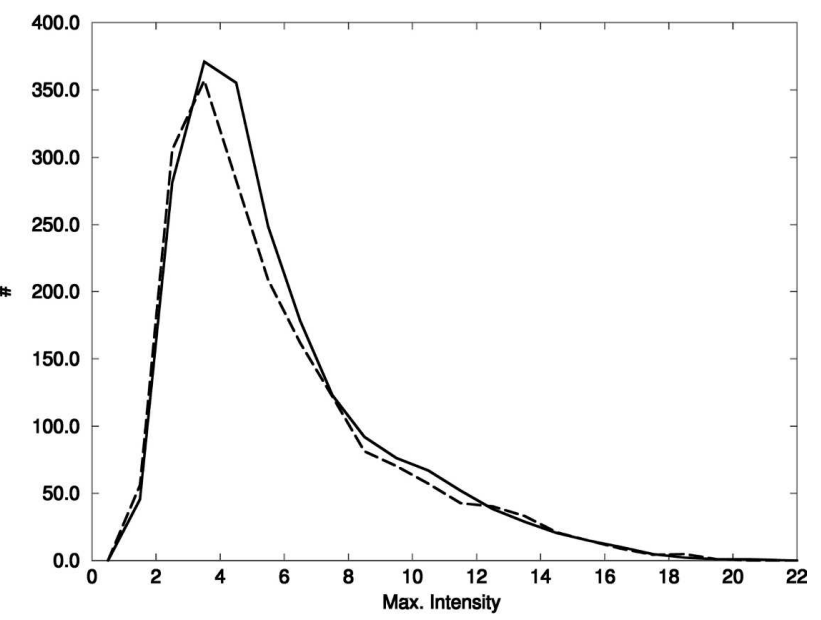

(d)

FIG. 16. Distributions of number of $\xi_{850}$ cyclonic systems for the May-October period vs their maximum intensity for 20C and 21C averaged over the three ensemble members for the Tropics. Systems must be initiated within $0^{\circ}-20^{\circ} \mathrm{N}$ and attain their maximum within $0^{\circ}-35^{\circ} \mathrm{N}$. (a) All the Tropics (number per month), with inset showing the tails; (b) Atlantic MDR $\left(8^{\circ}-35^{\circ} \mathrm{N}, 50^{\circ}-86^{\circ} \mathrm{W}\right)$; (c) eastern Pacific $\left(0^{\circ}-35^{\circ} \mathrm{N}, 90^{\circ}-135^{\circ} \mathrm{W}\right)$; and (d) western Pacific $\left(0^{\circ}-35^{\circ} \mathrm{N}, 110^{\circ} \mathrm{E}-180^{\circ}\right)$. The inset of (a) and (b), (c), and (d) are scaled to the full season (6 months) and for 30 years. Intensities are in units of $10^{-5} \mathrm{~s}^{-1}$; bin width is $1 \times 10^{-5} \mathrm{~s}^{-1}$.

due to zonal asymmetry in the SSTs. The reduced SST warming at high latitudes is a result of the more intense heat exchange with the deep ocean. This type of response is a common feature in coupled models when exposed to increased greenhouse gas forcing (Räisänen 2001).

The response pattern in the $\mathrm{NH}$ is more difficult to interpret, although even here a poleward transition of

TABLE 1. Mean and standard deviation of the number of storms per season for the NH (DJF) and SH (JJA) winters and the Tropics (May-October) and for storms exceeding an intensity value of $8.0 \times 10^{-5} \mathrm{~s}^{-1}$ in these periods.

\begin{tabular}{|c|c|c|c|c|c|c|}
\hline & \multicolumn{2}{|c|}{ All storms } & \multicolumn{2}{|c|}{ Storms $>8.0 \times 10^{-5} \mathrm{~s}^{-1}$} & \multicolumn{2}{|c|}{ ERA-40 (1979-2002) } \\
\hline & $20 \mathrm{C}$ & $21 \mathrm{C}$ & $20 \mathrm{C}$ & $21 \mathrm{C}$ & All & $>8.0 \times 10^{-5} \mathrm{~s}^{-1}$ \\
\hline NH (DJF) & $374.05 \pm 12.30$ & $358.13 \pm 11.49$ & $81.12 \pm 6.13$ & $79.82 \pm 6.06$ & $357.42 \pm 10.09$ & $85.0 \pm 6.04$ \\
\hline SH (JJA) & $381.03 \pm 12.09$ & $358.95 \pm 10.60$ & $122.86 \pm 7.04$ & $126.57 \pm 7.23$ & $369.12 \pm 13.13$ & $103.46 \pm 11.77$ \\
\hline Tropics & $277.33 \pm 19.58$ & $259.28 \pm 19.20$ & $40.55 \pm 4.77$ & $40.47 \pm 5.02$ & $247.58 \pm 16.84$ & $26.17 \pm 4.85$ \\
\hline
\end{tabular}




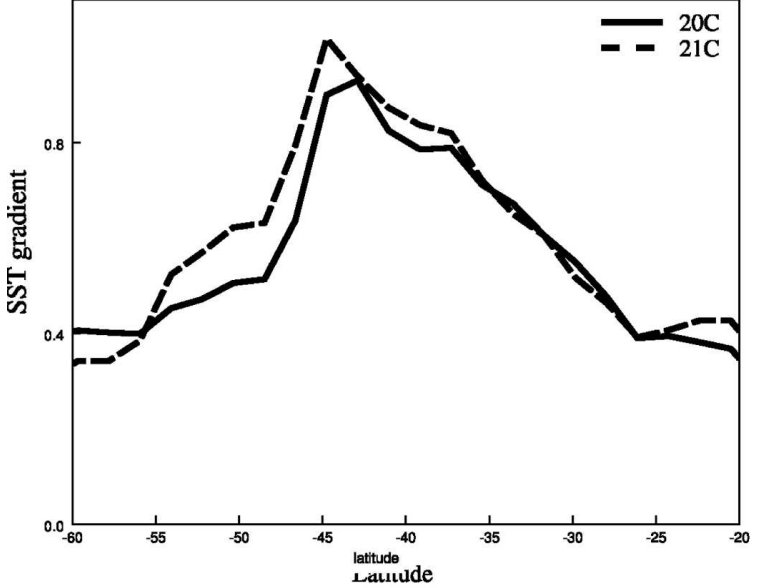

(a)

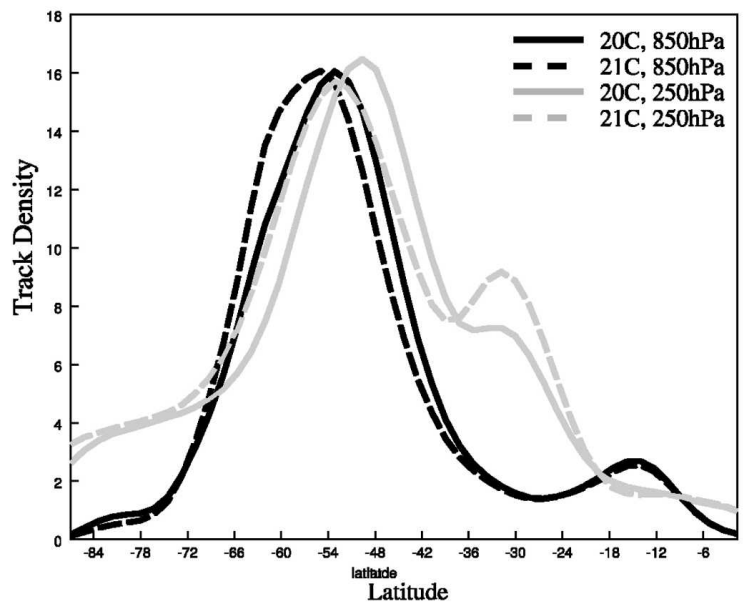

(c)

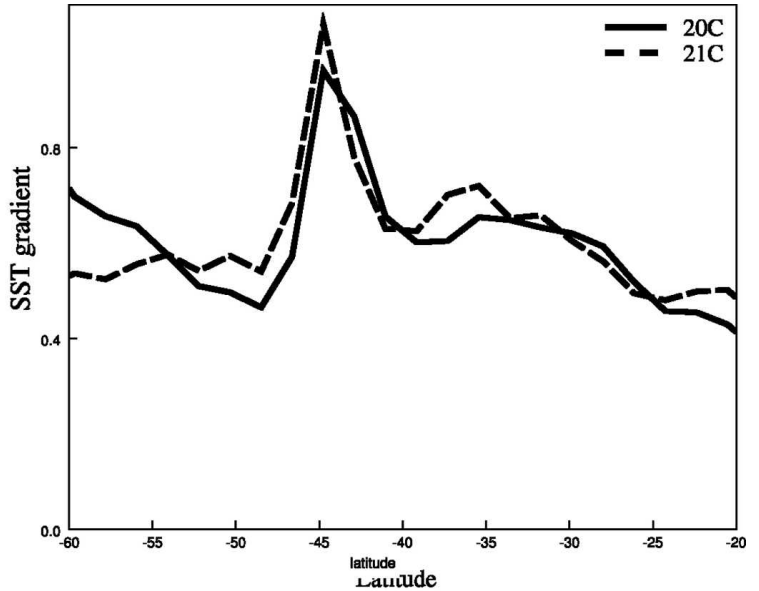

(b)

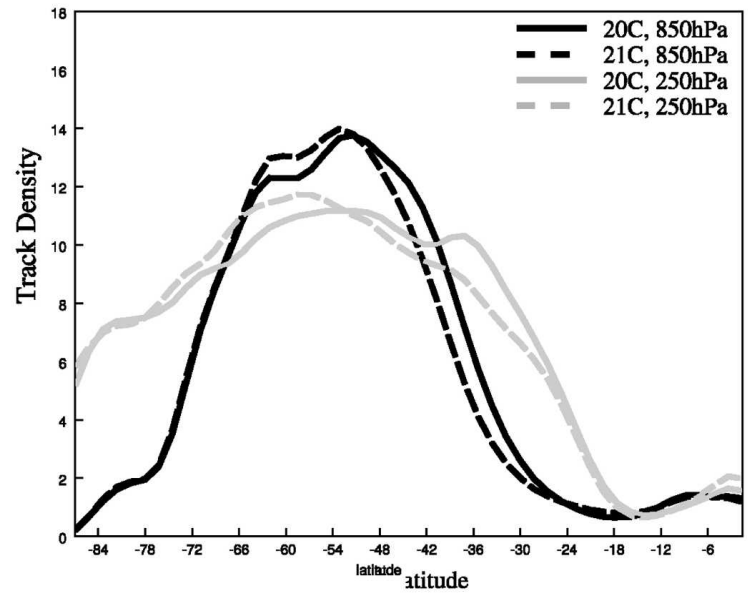

(d)

FIG. 17. SH zonal mean SST gradients and cyclonic track densities for 20C and 21C, respectively: (a) DJF SST gradients, (b) JJA SST gradients, (c) DJF track density for $\xi_{850}$ and $\xi_{250}$, and (d) JJA track density for $\xi_{850}$ and $\xi_{250}$. SST gradients in units of Kelvin per degree latitude and track densities in units of number density per month per unit area, where the unit area is equivalent to a $5^{\circ}$ spherical cap $\left(\sim 10^{6} \mathrm{~km}^{2}\right)$

the storm track can be identified. The weakening of the storm track over the Mediterranean seems to be related to a large-scale hemispheric change. However, there is an indication of an El Niño-type response, mainly affecting the storm track in the North Pacific with a minor effect over the United States. The storm track enhancement over the eastern North Atlantic is puzzling and could be a model bias reflecting a stronger response to ENSO as indicated in Fig. 9b, although a very similar increase in the storm tracks in the eastern North Atlantic is apparent in the Hadley Centre model (R. McDonald, Hadley Centre, 2005, personal communication). A contributing factor to the storm track intensification could be related to the strengthening of the SST gradient and associated increased baroclinicity in the central North Atlantic south of the area of minimum SST warming (not shown).

The tropical storm track changes are broadly consistent with the tropical SST changes and in particular with a proportional large warming in the tropical east Pacific. This means that the changes in the tropical storm tracks are similar to what happens during an El Niño event including a weakening of the tropical Atlantic storm track and a southward translation and strengthening of the east Pacific storm track. Earlier ECHAM coupled models had a similar response (Latif et al. 2000), but it could not be excluded that this typical response is model dependent.

We also note the remarkable observation of the capability of the model to broadly reproduce the distri- 
bution of storms as a function of intensity under different climate conditions when integrated over hemispheric or tropical domains. This may suggest an interesting invariant property of the transient storms, which is highly puzzling and may require further attention. See also Table 1, where we show the annual variability of storms. This is in contrast to some previous studies that have indicated an increase in the intensity of extreme storms. However, these studies have been predominately based on identifying minima in the MSLP field. As part of this study, MSLP data (with the planetary scales removed) have also been explored and produce broadly similar results to those for vorticity in terms of the spatial changes in storm track activity and the intensity distributions. To test if the large-scale background has any impact on the MSLP cyclone intensities, the tracks from this study have been referred back to the raw data to obtain the unfiltered pressure minima. This has been done by using the existing location of the pressure minima in the filtered field as starting points and searching for a minima within a $5^{\circ}$ radius (geodesic) in the raw pressure field using B-spline interpolation and a steepest descent minimization. Results for maximum intensity distributions for the filtered and unfiltered MSLP for the NH winter (DJF) are shown in Fig. 18. These show that for the filtered field the results are broadly in agreement with those for vorticity shown in section 5a, whilst, those for the unfiltered data show a distinct shift to deeper storms in the tail for $21 \mathrm{C}$ (note that the tail is on the right for the filtered data and on the left for the unfiltered data). This highlights that many of the previous studies, reliant on unmodified MSLP or surface geopotential data, where an increase in intensity of storms is observed on global domains, may just be reflecting changes in the large-scale background pressure field. This has also been highlighted by Sinclair and Watterson (1999).

Compared to previous studies on the change of storm tracks in a future climate as summarized by Geng and Sugi (2003), the following aspects of this study are highlighted: 1) This study has used data from a coupled model at relatively high resolution (compared with many previous studies) with observed anthropogenic forcing, including tropospheric and stratospheric ozone for the past century and a selected SRES scenario for the future. The analysis has made use of an ensemble of three 30-yr integrations. 2) The reduction of storms in the extratropics at both hemispheres is minor and only includes the weaker storms. 3) There is no indication of an increase in the intensity of extratropical storms except to a smaller degree in the $\mathrm{SH}$, which we suggest may be related to a poleward translation of the storm track. 4) There are no changes in the extremes of tropi-

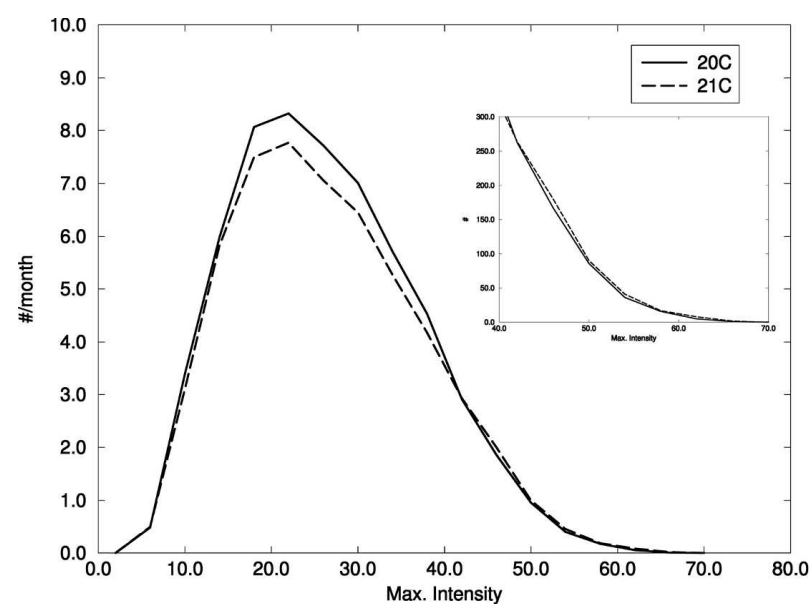

(a)

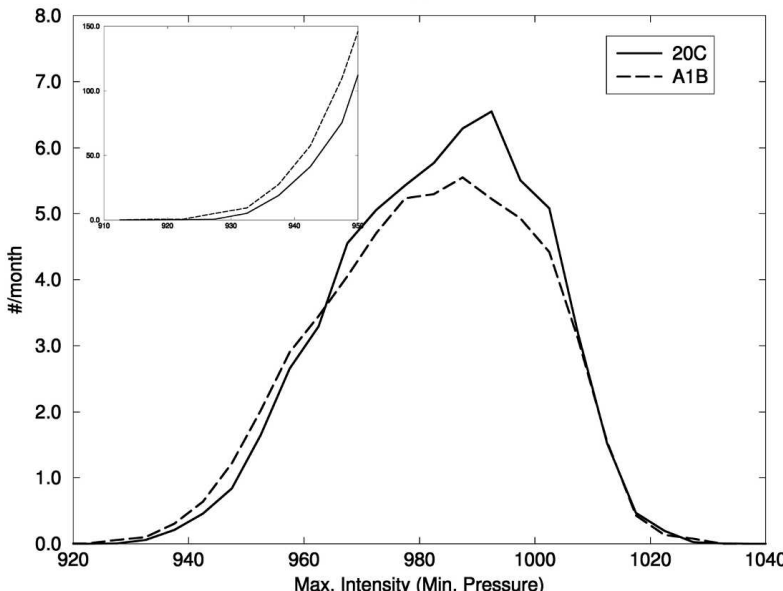

(b)

FIG. 18. NH distributions of number of MSLP cyclonic systems per month vs their maximum intensity for $20 \mathrm{C}$ and $21 \mathrm{C}$ averaged over the three ensemble members for $30^{\circ}-90^{\circ} \mathrm{N}$ : (a) for data with planetary scales removed and (b) for unfiltered data. The insets show the tails of the distributions scaled to the full season (3 months) and for 30 years. Intensities are in units of $\mathrm{hPa}$; bin widths are 4 and $5 \mathrm{hPa}$, respectively.

cal storms in spite of increased tropical SST by $2^{\circ}-3^{\circ} \mathrm{C}$. 5) The regional changes in the storm tracks are suggested to be associated with regional SST changes. The mechanisms for the tropical SST are consistent with Rossby wave propagation and the extratropical SST for the locking in of the storm tracks as suggested by Inatsu et al. (2002).

Finally, some shorter comments on the possible consequences for climate change projection are as follows: First, we see no indication of any dramatic changes in the number of storms and their intensity either in the extratropics or in the Tropics. The slight increased intensity in the SH is presumably a consequence of the southward movement of the storm track. However, the change in the position of the storm tracks mainly in the 
SH may have severe consequences for the water supply in southern Africa, southern Australia, and New Zealand. This is because a considerable part of the precipitation in these areas is related to transient cyclones. Similar problems may occur in the Mediterranean region and Middle East. These reductions in precipitating systems may have a "knock-on" effect on glaciation in mountainous regions such as the Alps. Such changes may be more demanding for society than higher temperatures. Changes seen in the North Atlantic may have an impact in terms of precipitation and of damaging winds on the British Isles and northwestern Europe. We believe, in conclusion, that studies of the modelcalculated storm tracks should be undertaken in other climate change models as a further important contribution to a more in-depth assessment of future climate change. In addition linking the storm track information with other quantities such as precipitation and winds will provide information on changes associated with the migratory storms and their change under climate change scenarios. Higher-resolution integrations are also required, in particular to resolve issues associated with tropical systems.

Finally some caveats on this study are as follows: We must caution against generalizing the results of this paper as the experiments have been restricted to one single coupled model. Another pattern of SST changes, for example, is expected to give rise to different regional changes in the storm tracks. However, the atmospheric version of the model is capable of reproducing essential features of the life cycle, distribution, and intensity of transient storms in the extratropics and to a reasonable degree also in the Tropics. For the present climate the coupled model generates very similar storm tracks as the atmospheric model, providing confidence in the overall results. A particular interesting feature is the overall robustness in the statistical distribution of storms. Using two days as a minimum lifetime and minimum displacements of $1000 \mathrm{~km}$ of the storms, a semiGaussian distribution curve is obtained with an extended tail toward the high end of the distribution representative of the most intense storms. We have investigated the tail of the distribution curve specifically and note a good agreement except for the Tropics, where all the model simulations underestimate the most extreme storms compared to ERA-40. We must therefore caution against drawing any general conclusion, in particular concerning small-scale intense vortices in the Tropics, as they are not properly resolved in this study. A higher-resolution study may not necessarily give the same result. However, the change in the number of storms as well as regional changes in the tropical storm tracks (as far as we can rely on the re- gional SST changes) are within the capacity of the model to handle. We consider also the present study to be broadly relevant for extratropical synoptic-scale storms as these are well resolved and simulated by the model in high agreement with ERA-40, although clearly, as with the Tropics, this study cannot provide information on smaller-scale storms (mesoscale) and any changes to them in the future climate due to the lack of resolution of the current model, the Regional Climate Models (RCM), are more likely to be useful in this respect. (Note that a full set of results are available at http://www.nerc-essc.ac.uk/ kih/IPCC/ipcc_results. html.)

Acknowledgments. The authors thank Dr. Ian Bland for making the computing resources available for the $p$ value calculations and ECMWF for the provision of the ERA-40 data. The authors would also like to thank the reviewers for their comments leading to an improved manuscript.

\section{APPENDIX}

\section{Revised Estimators for ENSO Composite Statistics}

Revised estimators for producing ENSO composite statistics from monthly Niño-3 index values, normalized and centered, are shown below.

Density estimation:

$$
\hat{f}(\mathbf{X})=\frac{\sum_{i=1}^{n} w_{i} K\left(\mathbf{X}_{i} \cdot \mathbf{X}\right)}{\sum_{i=1}^{n} w_{i}}
$$

Mean Attribute estimation:

$$
\hat{\mathbf{Y}}(\mathbf{X})=\frac{\sum_{i=1}^{n} w_{i} \mathbf{Y}_{i} K\left(\mathbf{X}_{i} \cdot \mathbf{X}\right)}{\sum_{i=1}^{n} w_{i} K\left(\mathbf{X}_{i} \cdot \mathbf{X}\right)}
$$

Effective number of data points:

$$
N_{e}=\frac{\sum_{i=1}^{n} w_{i}}{\sum_{I=1}^{M} w_{I}}
$$

where $\mathbf{X}_{i}$ is the unit vector to data point $i$ on the unit sphere, $\mathbf{Y}_{i}$ is data point $i$ value, either scalar or vector. The additional weights are chosen as

$w_{i}(I)=\tanh \left( \pm 1.5 W_{I}\right)$, if $\pm 1.5 W_{I}>0 ; \quad 0$ otherwise, where $w_{i}$ is the weight, dependent on year and month, for data point $i ; W_{I}$ is the monthly index value for 
month $I ; K(\cdot)$ is the spherical kernel; $n$ is the number of data points; and $M$ is the total number of months. See Hodges (1996) for further details on spherical kernel estimators.

\section{REFERENCES}

Bengtsson, L., 1991: Advances and prospects in numerical weather prediction. Quart. J. Roy. Meteor. Soc., 117, 855-902.

— M. Botzet, and M. Esch, 1995: Hurricane-type vortices in a general circulation model. Tellus, 47A, 175-196.

$\_,-$_ and —_, 1996: Will greenhouse gas induced warming over the next 50 years lead to higher frequency and greater intensity of hurricanes? Tellus, $\mathbf{4 8 A}, 57-73$.

,$- \ldots$, and — 1997: Numerical simulations of intense tropical storms. Hurricanes, H. F. Diaz and R. S. Pulwarty, Eds., Springer-Verlag, 67-90.

_ - S. Hagemann, and K. I. Hodges, 2004: Can climate trends be calculated from reanalysis data? J. Geophys. Res., 109, D11111, doi:10.1029/2004JD004536.

Camargo, S. J., and A. H. Sobel, 2004: Formation of tropical storms in an atmospheric general circulation model. Tellus, 56A, 56-67.

Carnell, R. E., C. A. Senior, and J. F. B. Mitchell, 1996: An assessment of measures of storminess: Simulated changes in northern hemisphere winter due to increasing $\mathrm{CO}_{2}$ Climate Dyn., 12, 467-476.

Egger, J., 1977: On the linear theory of the atmospheric response to sea surface temperature anomalies. J. Atmos. Sci., 34, 603614.

Fyfe, J. C., 2003: Extratropical Southern Hemisphere cyclones: Harbingers of climate change. J. Climate, 16, 2802-2805.

Geng, Q., and M. Sugi, 2003: Possible change of extratropical cyclone activity due to enhanced greenhouse gases and sulfate aerosols-Study with a high-resolution AGCM. J. Climate, 16, 2262-2274.

Gray, W. M., 1979: Hurricanes: Their formation, structure and likely role in the tropical circulation. Meteorology over the Tropical Oceans, D. B. Shaw, Ed., Royal Meteorological Society, 155-218. [Available from Royal Meteorological Society, James Glaisher House, Grenville Place, Bracknell, Berkshire RG12 1BX, United Kingdom.]

Held, I. M., 1993: Large-scale dynamics and global warming. Bull. Amer. Meteor. Soc., 74, 228-241.

Hodges, K. I., 1995: Feature tracking on the unit sphere. Mon. Wea. Rev., 123, 3458-3465.

- 1996: Spherical nonparametric estimators applied to the UGAMP model integration for AMIP. Mon. Wea. Rev., 124, 2914-2932.

_ 1999: Adaptive constraints for feature tracking. Mon. Wea. Rev., 127, 1362-1373.

—, B. J. Hoskins, J. Boyle, and C. Thorncroft, 2003: A comparison of recent reanalysis datasets using objective feature tracking: Storm tracks and tropical easterly waves. Mon. Wea. Rev., 131, 2012-2037.

,,--- , and $\longrightarrow, 2004$ : Corrigendum. Mon. Wea. Rev., 132, 1325-1327.

Hoskins, B. J., and D. J. Karoly, 1981: The steady linear response of a spherical atmosphere to thermal and orographic forcing. J. Atmos. Sci., 38, 1179-1196.

— , and K. I. Hodges, 2002: New perspectives on the Northern
Hemisphere winter storm tracks. J. Atmos. Sci., 59, 10411061.

— and - 2005: A new perspective on Southern Hemisphere storm tracks. J. Climate, 18, 4108-4129.

Hurrell, J. W., Y. Kushnir, G. Ottersen, and M. Visbeck, 2003: The North Atlantic Oscillation: Climate Significance and Environmental Impact. Geophys. Monogr., Vol. 134, Amer. Geophys. Union, $279 \mathrm{pp}$

Inatsu, M., and B. J. Hoskins, 2004: The zonal asymmetry of the Southern Hemisphere winter storm track. J. Climate, 17, 4882-4892.

- H. Mukougawa, and S. Xie, 2002: Tropical and extratropical SST effects on the midlatitude storm track. J. Meteor. Soc. Japan, 80, 1069-1076.

Jungclaus, J., and Coauthors, 2006: Ocean circulation and tropical variability in the coupled model ECHAM5/MPI-OM. J. Climate, in press.

Knutson, T. R., and R. E. Tuleya, 2004: Impact of $\mathrm{CO}_{2}$-induced warming on simulated hurricane intensity and precipitation: Sensitivity to the choice of climate model and convective parameterization. J. Climate, 17, 3477-3495.

Kushner, P. J., I. M. Held, and T. L. Delworth, 2001: Southern Hemispheric atmospheric circulation response to global warming. J. Climate, 14, 2238-2249.

Lambert, S. J., 1995: The effect of enhanced greenhouse warming on winter cyclone frequencies and strengths. J. Climate, 8, 1447-1452.

Latif, M., E. Roeckner, U. Mikolajewicz, and R. Voss, 2000: Tropical stabilization of the thermohaline circulation in a greenhouse warming simulation. J. Climate, 13, 1809-1813.

Lau, N.-C., 1988: Variability of the observed midlatitude storm tracks in relation to low-frequency changes in the circulation pattern. J. Atmos. Sci., 45, 2718-2743.

Leckebusch, G. C., and U. Ulbrich, 2004: On the relationship between cyclones and extreme windstorm events over Europe under climate change. Global Planet. Change, 44, 181-193.

Marsland, S. J., H. Haak, J. H. Jungclaus, M. Latif, and F. Roeske, 2003: The Max-Planck-Institute global ocean/sea ice model with orthogonal curvilinear coordinates. Ocean Modell., 5, 91-127.

McDonald, R. E., D. G. Bleaken, D. R. Cresswell, V. D. Pope, and C. A. Senior, 2005: Tropical storms: Representation and diagnosis in climate models and the impacts of climate change. Climate Dyn., 25, 19-36.

Molinari, J., D. Knight, M. Dickinson, D. Vollaro, and S. Skubis, 1997: Potential vorticity, easterly waves, and eastern Pacific tropical cyclogenesis. Mon. Wea. Rev., 125, 2699-2708.

Muller, W. A., and E. Roeckner, 2006: ENSO impact on midlatitude circulation patterns in future climate change projections. Geophys. Res. Lett., 33, L05711, doi:10.1029/2005GL025032.

Nakicenovic, N., and Coauthors, 2000: Special Report on Emissions Scenarios. Cambridge University Press, 599 pp.

Petterssen, S., 1956: Weather Analysis and Forecasting. Vol. 1. McGraw-Hill, 428 pp.

Pham, M., O. Boucher, and D. Hauglustaine, 2005: Changes in atmospheric sulfur burdens and concentrations and resulting radiative forcings under IPCC SRES emission scenarios for 1990-2100. J. Geophys. Res., 110, D06112, doi:10.1029/ 2004JD005125.

Räisänen, J., 2001: $\mathrm{CO}_{2}$-induced climate change in CMIP2 experiments: Quantification of agreement and role of internal variability. J. Climate, 14, 2088-2104.

Roeckner, E., and Coauthors, 2003: The atmospheric general cir- 
culation model ECHAM 5. Part I: Model description. MPI Rep. 349, 127 pp.

— , and Coauthors, 2004: Sensitivity of simulated climate to horizontal and vertical resolution. MPI Rep. 354, $56 \mathrm{pp}$.

Rogers, J. C., 1997: North Atlantic storm track variability and its association with the North Atlantic Oscillation and climate variability of northern Europe. J. Climate, 10, 1635-1647.

Schneider, E. K., D. G. DeWitt, A. Rosati, B. P. Kirtman, L. Ji, and J. J. Tribbia, 2003: Retrospective ENSO forecasts: Sensitivity to atmospheric model and ocean resolution. Mon. Wea. Rev., 131, 3038-3060.

Schubert, M., J. Perlwitz, R. Blender, K. Fraedrich, and F. Lunkeit, 1998: North Atlantic cyclones in $\mathrm{CO}_{2}$ induced warm climate simulations: Frequency, intensity, and tracks. Climate Dyn., 14, 827-837.

Shukla, J. S., and Coauthors, 2000: Dynamical seasonal prediction. Bull. Amer. Meteor. Soc., 81, 2593-2606.

Sinclair, M. R., and I. G. Watterson, 1999: Objective assessment of extratropical weather systems in simulated climates. J. Climate, 12, 3467-3485.

Sugi, M., A. Noda, and N. Sato, 2002: Influence of the global warming on tropical cyclone climatology: An experiment with the JMA global model. J. Meteor. Soc. Japan, 80, 249272 .

Thompson, D. W. J., and J. M. Wallace, 1998: The arctic oscillation signature in the wintertime geopotential height and temperature fields. Geophys. Res. Lett., 25, 1297-1300.
Thorncroft, C., and K. Hodges, 2001: African easterly wave variability and its relationship to Atlantic tropical cyclone activity. J. Climate, 14, 1166-1179.

Ting, M.-F., and I. M. Held, 1990: The stationary wave response to a tropical SST anomaly in an idealized GCM. J. Atmos. Sci., 47, 2546-2566.

Uppala, S. M., and Coauthors, 2005: The ERA40 reanalysis. Quart. J. Roy. Meteor. Soc., 131, 2961-3012.

van Loon, H., and J. C. Rogers, 1978: The seesaw in winter temperatures between Greenland and northern Europe. Part I: General description. Mon. Wea. Rev., 106, 296-310.

van Oldenborgh, G. J., S. Philip, and M. Collins, 2005: El Niño in a changing climate: A multi-model study. Ocean Sci. Discuss., 2, 267-298.

WGNE, 1996: AMIP II guidelines. Atmospheric Model Intercomparison Project Newsletter, No. 8, AMIP Project Office, Livermore, CA, 24 pp. [Available from AMIP Project Office, PCMDI, L-264, LLNL, P.O. Box 808, Livermore, CA 94550.]

Wiedenmann, J. M., A. R. Lupo, I. I. Mokhov, and E. A. Tikhonova, 2002: The climatology of blocking anticyclones for the Northern and Southern Hemispheres: Block intensity as a diagnostic. J. Climate, 15, 3459-3473.

Zhang, Y., and W.-C. Wang, 1997: Model-simulated northern winter cyclone and anticyclone activity under a greenhouse warming scenario. J. Climate, 10, 1616-1634.

, J. M. Wallace, and D. S. Battisti, 1997: ENSO-like interdecadal variability, 1900-93. J. Climate, 10, 1004-1020. 